\title{
THESIS
}

\section{AGRONOMIC FACTORS AFFECTING DRYLAND GRAIN SORGHUM MATURITY AND PRODUCTION IN NORTHEAST COLORADO}

\author{
Submitted by \\ Sally M. Sauer \\ Department of Soil and Crop Sciences
}

In partial fulfillment of the requirements

For the Degree of Master of Science

Colorado State University

Fort Collins, Colorado

Summer 2012

Master's Committee:

Advisor: Jerry J. Johnson

Neil C. Hansen

Ajay K. Jha Gregory S. McMaster

Merle F. Vigil 
Copyright by Sally Marie Sauer 2012

All Rights Reserved 


\begin{abstract}
AGRONOMIC FACTORS AFFECTING DRYLAND GRAIN SORGHUM MATURITY AND PRODUCTION IN NORTHEAST COLORADO
\end{abstract}

Grain sorghum [Sorghum bicolor (L.) Moench] is an important crop in southeast Colorado, but little sorghum is produced in the northeast part of the state. Grain producers in northeast Colorado are interested in growing grain sorghum due to its drought tolerance and lower cost of inputs compared to corn. The main reason sorghum is not widely produced in northeast Colorado is because the shorter growing season reduces the chance that sorghum will reach physiological maturity before the first fall frost, which can significantly decrease grain yield and test weight. The main objective of this thesis was to determine if dryland grain sorghum could be produced in northeast Colorado by incorporating certain agronomic practices and selecting hybrids with the appropriate maturity. We hypothesized the agronomic treatments would have a significant impact on the cumulative GDD to maturity. A second objective of the study was to calculate the probability of the hybrids reaching maturity at different hypothetical planting dates at Akron and Fort Collins. We hypothesized the probability of the hybrids reaching maturity at Akron would be high, and the probabilities would be lower at Fort Collins based on the shorter growing season. The last objective of the thesis was to determine the effects of two different water treatments on grain yield of four hybrids, where we hypothesized the limited irrigation treatment would yield lower than the full irrigation treatment.

Three agronomic factors, row spacing $(0.76$ and $1.5 \mathrm{~m})$, seeding rate $(3,11$, and 20 seeds $\mathrm{m}^{-2}$ ), and row orientation (north/south and east/west) were studied along with hybrids (88P68- 
early maturity, DKS29-28-early maturity, and 5745-medium-early maturity) differing in maturity class. The maturity study was conducted at two locations in 2010 (Akron and Stratton) and two locations (Akron and Fort Collins) in 2011. In the maturity study, growing degree-days (GDD) were used to measure the amount of thermal time required from planting for the plants to reach physiological maturity in each treatment. Grain yield, test weight, plant population, and flowering measurements were taken in the four trials in addition to the maturity measurements. Probabilities of hybrids reaching physiological maturity at Akron and Fort Collins were calculated. Additional trials were conducted at Greeley in 2011 to determine the effects of two irrigation treatments (full and limited) on hybrid (CGSH-9-early maturity, 88P68, DKS29-28, and 5745) grain yield.

The maturity study results from treatments in the north/south row orientation (hybrid, row spacing, and seeding rate) showed hybrid selection, seeding rates, and the production environment effects were all significant. The two earlier maturing hybrids (88P68 and DKS2928) required significantly fewer GDD to reach maturity than the medium-early hybrid (5745). As seeding rates increased from 3 to 20 seeds $\mathrm{m}^{-2}$, significantly fewer GDD were required for the hybrids to reach maturity. The cumulative GDD required for maturity was significantly lower in 2011 than in 2010. The hybrid and environment results from treatments in the east/west row orientation (row spacing and hybrid) showed the two early maturity hybrids required significantly fewer GDD to reach maturity than the later maturity hybrid. The row orientation treatment did not have an effect on maturity. The expected probability of the hybrids reaching maturity at Akron was high for all three hypothetical planting dates (max of 97\% for May 15, 91\% for May 23, and $81.5 \%$ for June 1). At Fort Collins, the probabilities were much lower (max of 73.5\%), especially for the medium-early maturity hybrid, 5745 ( $\max$ of $57.5 \%$ ). The 
earlier the sorghum GDD accumulation start date, the greater the probability the sorghum would reach maturity at both locations, showing the importance of planting date and hybrid selection.

Yield results for the maturity study showed hybrid, seeding rate, and environment main effects were all significant. The environment by row spacing two-way interaction was significant due to different optimal row spacings in different environments. The 88P68 hybrid yielded significantly lower than the other two hybrids. The seeding rate of 3 seeds $\mathrm{m}^{-2}$ yielded significantly lower than the two higher seeding rates. Fort Collins (2011 only) yielded significantly higher than the other three trial environments. At Greeley in 2011, the two irrigation regimes had a significant effect on the yield of all hybrids. The full-irrigation yield was significantly higher than the limited-irrigation yield under high drought and heat conditions in 2011. Grain test weight from experiment 1 (north/south row orientation with hybrid, seeding rate, and row spacing treatments) in 2011 at Akron and Fort Collins showed that interactions among all trial factors were significant. Environment, row spacing, and hybrid were each significant effects. Test weight was significantly lower at the $0.76 \mathrm{~m}$ row spacing than in the 1.5 m row spacing. The Akron location had significantly higher test weight than Fort Collins.

Overall results from the grain sorghum studies showed grain sorghum could be reliably produced in northeast Colorado. The maturity study provided valuable information that could apply to specific situations (such as re-plants or late-plantings) in other areas where early maturity in grain sorghum may be important. Hybrid selection and planting date are two of the most important factors that can affect the cumulative GDD required for grain sorghum to reach physiological maturity. Different hybrids can take significantly different amounts of cumulative GDD to reach maturity depending on the genetics. Hybrid selection should be based on the relative maturity and yield of the cultivar, along with other characteristics depending on the 
growing conditions. The planting date of grain sorghum can have a substantial impact on the probability of grain sorghum reaching maturity as the probability of reaching maturity can be increased by planting as early as possible in the growing season. Less important factors affecting the cumulative GDD to maturity are seeding rate and environment. Results from the study showed that as seeding rates increased, cumulative GDD to maturity decreased. The row spacing and orientation factors did not affect the cumulative GDD to maturity.

Grain yield and test weight were both significantly affected by growing environments and hybrid factors. Water availability in the environment is the most important factor as it can significantly affect both grain yield and test weight. Yield can also be significantly increased by using the appropriate row spacing depending on water availability. A notable trend from the yield and test weight results showed there was a trade-off between yield and test weight.

The results from the thesis project show the importance of agronomic and environmental factors in grain sorghum production in Colorado. Our hypothesis that the agronomic factors would have a significant impact on the cumulative GDD to maturity was partially correct since seeding rate and hybrid main effects were significant. We found that earlier maturity cultivars can be produced at Akron with reasonable confidence (minimum probability was $81 \%$ for the early maturity hybrids) they will reach physiological maturity before the first freeze. Future research on factors affecting grain sorghum maturity could include additional hybrid and seeding rate treatments as well as a planting date factor. The creation of a map of northeast Colorado with hypothetical probabilities of grain sorghum hybrids reaching physiological maturity could also be done to give producers a useful production tool. The row orientation factor does not warrant further research for its effect on grain sorghum maturity and additional growing 
environments would not be necessary for future research since environments could be modeled to determine adaptability. 


\section{ACKNOWLEDGMENTS}

Many individuals are responsible for helping complete this project. I would like to thank my committee members, Merle Vigil, Greg McMaster, Neil Hansen, and Ajay Jha for their encouragement, feedback, and patience with my thesis project. My advisor, Jerry Johnson, was crucial to the completion of this thesis and I am very thankful for his guidance, enthusiasm, and constant encouragement during my time in graduate school. I am especially appreciative of Jerry providing an assistantship and allowing me to work as a part-time graduate assistant for the Crops Testing Program while attending graduate school. The experience I have gained from the job has been invaluable. I am also grateful to the Colorado Sorghum Producers who helped fund part of my graduate research.

I am thankful for the help received from Jim Hain for sharing his grain sorghum production expertise by answering my questions and giving input on different production aspects of the project. He also took time to help pick out sites, plant, fertilize, take flowering notes, and harvest the trials. Others who helped manage the field trials include Jerry Buchleiter, Chris Fryrear, and Mark Collins. Kevin Larson shared his knowledge of grain sorghum production and physiology with me, and he was a great resource, especially during the early phases of my thesis project. David Nielsen generously provided guidance and weather data for calculating the probabilities of the hybrids reaching maturity. I appreciate statistical guidance given by Phil Chapman, who assisted with the design and analysis of my field trials. Fellow graduate students who provided general help and support with my thesis project include Mohammad Navid Sediqi and Freeborn Garrett Jewett. Undergraduate students who assisted in the less-fun jobs involved in running field trials include Joanna Shefford and Jeff Orton. 
My family has been wonderfully supportive and patient and I am especially grateful to my husband Jason for his love and encouragement during the course of my studies. He provided help and expertise in the field, and he also took on extra responsibilities at home to allow me to focus on my studies. I am thankful to my parents, Pauli Ann Jones and Kim Jones, who regularly shared their enthusiasm and support of my work. I could always count on my mom's reassurance when I became discouraged, and she was quick to offer a helping hand whenever possible. I am very appreciative of her and my brother Andy taking field notes at Stratton, which saved me countless hours on the road during the busy school year.

Last, but certainly not least, I would like to express my sincere gratitude to the hardworking farmers who help to provide food, fiber, and fuel for the human population. They rarely get the recognition they deserve from the people who reap the benefits of their work on a daily basis. 


\section{DEDICATION}

I dedicate this thesis to my mother, Pauli Ann Jones.

After being a farmer's wife and a stay-at-home mom for almost twenty years, she went back to school to finish her Bachelor's degree and to earn her Master's degree, doing both while teaching

full-time and raising three kids. She taught me the value of hard work and the importance of having the courage to always do the right thing. I am forever grateful to her for the sacrifices she made for us, and without her, I would not be where I'm at today. 


\section{TABLE OF CONTENTS}

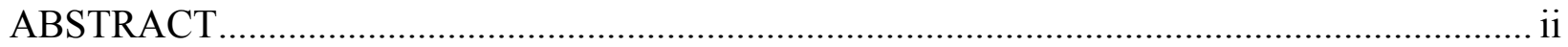

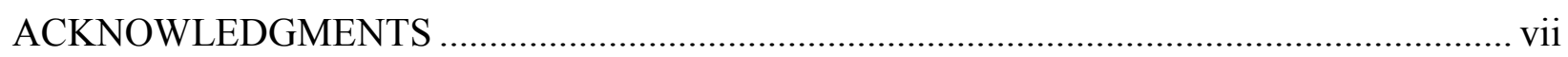

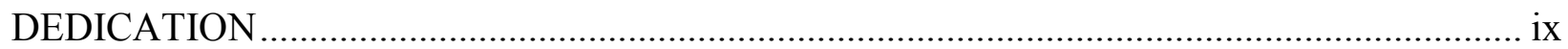

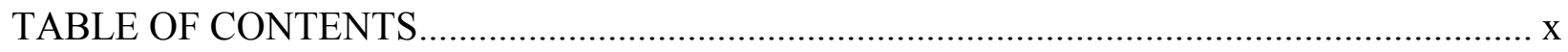

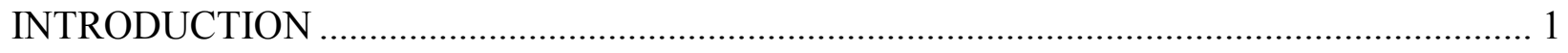

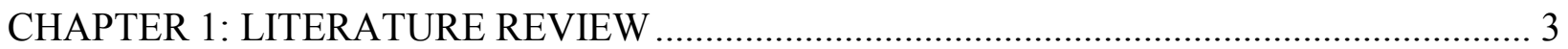

Background and Importance ………………………….................................................... 3

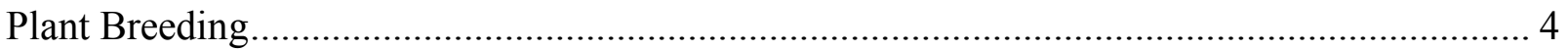

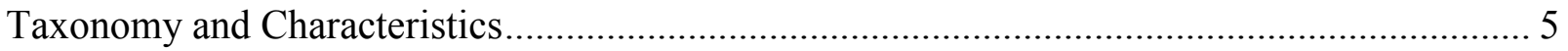

Adaptation, Production, and Uses................................................................................... 7

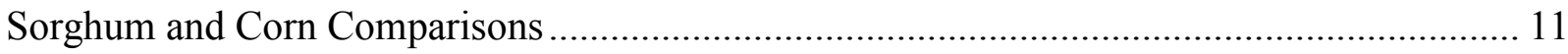

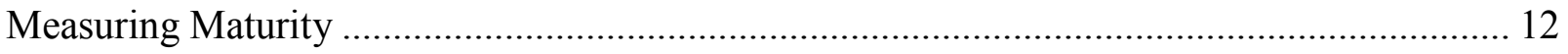

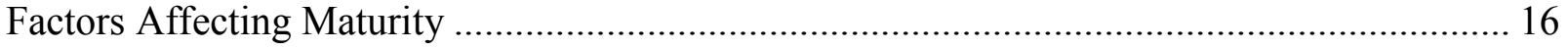

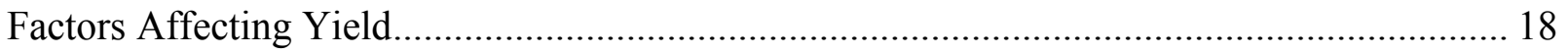

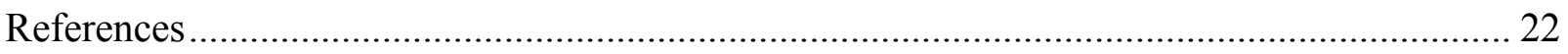

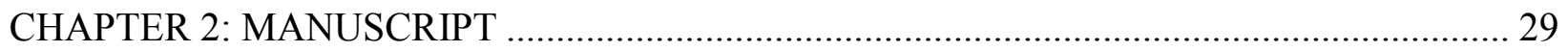

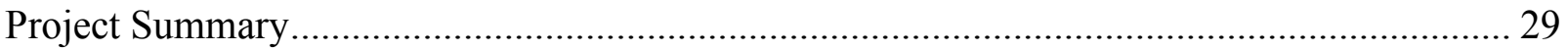

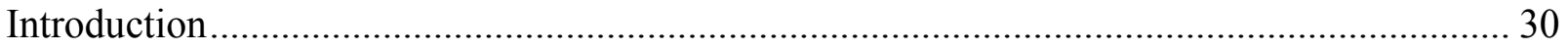

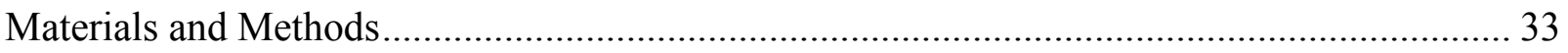

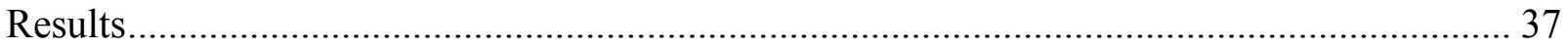


Climate

Maturity. 37

Yield. 41

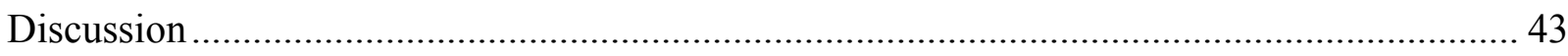

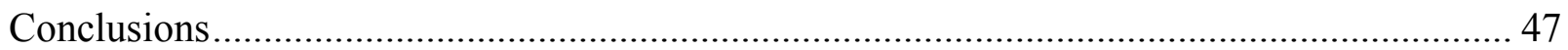

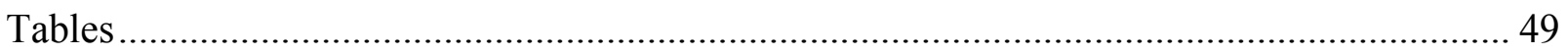

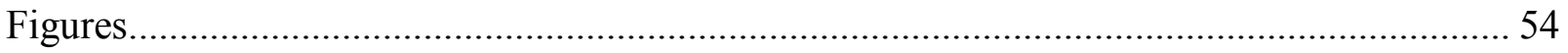

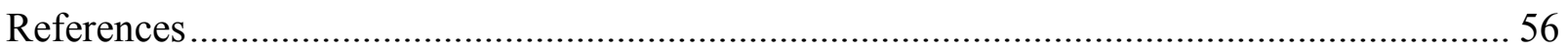

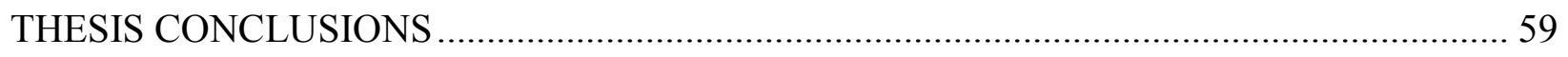

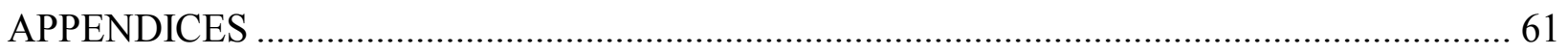

APPENDIX I: Test Weight Analysis Results, Additional Test Weight Data, and 2011 Greeley

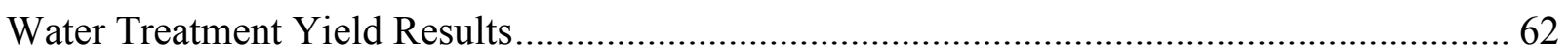

APPENDIX II: Additional Yield, Population, Flowering, Maturity, and Lodging Data from

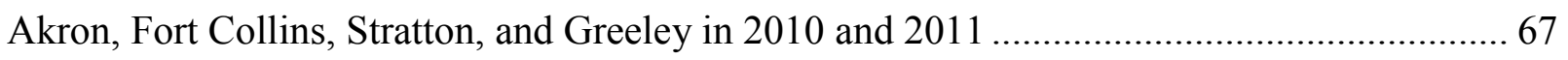

APPENDIX III: My Sorghum Presentations ............................................................... 76 


\section{INTRODUCTION}

Grain sorghum [Sorghum bicolor (L.) Moench] is produced on many acres in southeast Colorado, but few acres are dedicated to sorghum production in the northeast part of the state. The main reason sorghum is not widely produced in northeast Colorado is the short growing season, which can prevent the sorghum from reaching physiological maturity before the first fall frost during some years. Freezing air temperatures that occur before the plant fully matures can significantly decrease the grain yield and test weight of the crop. The lack of herbicide resistance in sorghum, along with competition from dryland corn, both contribute to low production acreage in northeast Colorado. If grain sorghum could be reliably produced in northeast Colorado, producers in the area would have another crop they could incorporate into their winter wheat-based crop rotations.

The main objective of the study was to determine if dryland grain sorghum can be reliably produced in northeast Colorado by using agronomic and other and management practices (such as hybrid selection) to help the sorghum reach physiological maturity before a frost occurs in the fall. The second objective was to determine the probability of sorghum reaching physiological maturity in northeast Colorado based on historic climate data and sorghum maturity data collection during the study. The third objective was to measure the effects of irrigation on overall grain yield, compared to non-irrigated grain sorghum.

Grain sorghum was the crop chosen to be studied because of its high drought tolerance and its lower cost of production than its main dryland crop competitor, corn. Grain sorghum seed costs are much lower than corn, and sorghum can be produced using wheat or corn equipment such as planters, drills, and combine headers that farmers may already own. Sorghum 
is usually planted two to four weeks after corn, which can allow extra time in the spring for weed control using mechanical or herbicide options before the crop is planted.

Grain sorghum ranks fifth for world cereal production, behind wheat, maize, rice, and barley. The main uses for grain sorghum in the United States are cattle feed, ethanol production, birdseed, and in human food production as a substitute for wheat in gluten-free products.

Colorado was the fourth largest producer in the United States in 2011, behind Texas, Kansas, and Oklahoma. 


\section{CHAPTER 1}

\section{LITERATURE REVIEW}

\section{Background and Importance}

Sorghum [Sorghum bicolor (L.) Moench] has been cultivated in arid and semiarid regions of Africa for thousands of years. It originated in North Africa and was domesticated in present day Ethiopia between 4,000 and 3,000 B.C. (Dillon et al., 2007; Doggett, 1970). Sorghum later spread to other parts of Africa and eventually to India, the Middle East, and China (Doggett, 1970). The first written record of sorghum is from the first century A.D., found in writings by the Roman, Pliny (Martin, 1970; Smith and Frederiksen, 2000). Grain sorghum was first introduced to North America through the West Indies by slave ships during the 17th century, but even after widespread distribution, production slowly dropped off until it disappeared (Maunder, 1999). The next introduction of grain sorghum into America occurred in California in 1874. Shortly after grain sorghum was re-introduced, it became widespread in the southern Great Plains and other arid regions of the United States due to its ability to produce more than corn under drought conditions (Smith and Frederiksen, 2000).

Grain sorghum is the fifth most important cereal crop in world and the third most important cereal crop in the United States after corn and wheat (FAS/USDA, 2011). Worldwide, sorghum production was 66.2 million metric tons for the 2010-2011 trade year (October through September), with the United States being the world's second largest producer, behind Nigeria (FAS/USDA, 2011). In 2010, over 7.5 million metric tons of sorghum was harvested in the United States with the value of production totaling more than 1.7 billion dollars (USDA, 2011). 
Colorado ranked as the fourth largest grain sorghum producing state in 2011, behind Kansas, Texas, and Oklahoma, with a total value of production of over 37 million dollars in 2010 (USDA, 2011). Over 50 percent of Colorado's total sorghum production in 2010 was from three counties in the southeast portion of the state (Baca, Kiowa, and Prowers), with the total production equaling 191,000 metric tons. The United States is the world's largest exporter of grain sorghum, exporting 2.4 million tons in the 2010-2011 trade year, while Mexico and Japan are the leading importers of sorghum (FAS/USDA, 2011).

\section{Plant Breeding}

Grain sorghum production in the United States increased rapidly in the late 1800's and new varieties better adapted to the Great Plains region were developed through the selection of desirable off-type plants from mutations or natural hybridizations (Poehlman, 1987). Sorghum is a diploid containing ten chromosome pairs and is self-pollinating, although outcrossing occurs around six percent of the time (Doggett, 1970; Poehlman, 1987; Rooney, 2000). Breeding of sorghum hybrids began around 1925, but in 1950 cytoplasmic male sterility was discovered in grain sorghum and became the basis for hybrid seed production (Poehlman, 1987; Rooney, 2000). Grain sorghum selection and breeding mainly focused on creating plants that were short statured for mechanical harvest, early maturing, and higher yielding than the original varieties that were introduced from the tropics. Dwarf sorghum cultivars were created by making three of the four different independent height gene alleles $\left(\mathrm{Dw}_{1}\right.$ through $\left.\mathrm{Dw}_{4}\right)$ recessive (three-gene dwarfs). Four-gene dwarfs are not used due to decreased yield, and two gene dwarfs create plants that are tall enough to be prone to lodging (Poehlman, 1987).

Maturity in grain sorghum was shortened by utilizing six gene loci $\left(\mathrm{Ma}_{1}\right.$ through $\left.\mathrm{Ma}_{6}\right)$ that can be manipulated to make the plants fit shorter growing seasons (Poehlman, 1987; Rooney 
and Aydin, 1999; Quinby and Karper, 1945). The plants flower sooner when one or more of the maturity genes are recessive, which also makes the sorghum plants completely photoperiod insensitive (Rooney and Aydin, 1999). Sorghum grain yield potential in the United States has increased markedly since its introduction and the increases are attributed to the development of hybrids and short-stature plants that can be grown in high-yielding environments. Breeding programs are utilizing genetics to create cold tolerant hybrids that are able to germinate at lower temperatures, along with hybrids that have open panicles and are photoperiod insensitive to allow sorghum to be better adapted to regions with shorter growing seasons (Poehlman, 1987). Disease and insect resistance has become an important part of many breeding programs to help prevent crop losses from grain molds and foliar diseases, and from insects such as greenbugs and the sorghum midge (Rooney, 2000). Hybrids resistant to herbicides such as acetolactate synthase (ALS) and acetyl-coenzyme A carboxylase (ACCase) have also been created to allow for better weed control in fields, although none of these hybrids have been commercially released as of early 2012 .

\section{Taxonomy and Characteristics}

All sorghums belong in the Poaceae grass plant family, and in the Sorghinae sub-tribe within the Andropogoneae plant tribe (Dahlberg, 2000). The genus Sorghum includes three species: bicolor, propinquum, and halepense, with Sorghum bicolor containing all of the cultivated sorghums. Both Sorghum propinquum and Sorghum halepense are rhizomatous wild, weedy perennials that are able to cross with Sorghum bicolor (de Wet, 1978). Sorghum bicolor (L.) Moench is further divided into three subspecies, Sorghum bicolor subsp. bicolor, Drummondii, and Verticilliforum (formerly known as Arundinaceum). The latter two subspecies are annual weeds (Dahlberg, 2000; de Wet, 1978). 
The cultivated subspecies bicolor consists of five different races, which can combine with each other to produce ten hybrid intermediate races, totaling 15 races all together (Dahlberg, 2000; de Wet, 1978). The race bicolor is large and complex, consisting of many different subraces that produce small amounts of grain and that are mainly used as forage. One of the most important sub-races of the race bicolor is sorgo, which contains many of the sweet sorghum cultivars that are used for syrup production. Another race, guinea, is well adapted to highrainfall environments and is very important in West Africa where it is widely grown for human consumption. The race durra contains the most drought tolerant cultivars that are grown in the Near East, Ethiopia, and India, and were once popular in the United States where they were commonly called milo (Harlan and de Wet, 1972). A fourth race, caudatum, is known for its high grain yield potential and high seed quality (Dahlberg, 2000; Harlan and de Wet, 1972). The last race, kafir, is agronomically important due to its high yield potential and closed to semi-open panicle structure (Harlan and de Wet, 1972). The kafir-caudatum intermediate race is the most important for grain sorghum production in the United States today, as most hybrid grain sorghums are of this intermediate race (Harlan and de Wet, 1972).

Grain sorghum is a perennial that is treated as an annual plant in many parts of the world where it is grown. It has ten distinct growth stages that were defined by Vanderlip and Reeves in 1972 by using predominate characteristics for each stage. The emergence of the seedling is denoted as growth stage zero and is defined as when the coleoptile becomes visible above the soil surface. Stages one and two occur when the third and fifth leaf collars, respectively, are visible on the culm. The third stage occurs when the growing point shifts from vegetative growth to reproductive growth and this is when the main stem begins to elongate to form the peduncle (Vanderlip and Reeves, 1972). This stage marks the beginning of the critical growth 
period as any environmental stresses such as drought or extreme temperatures will negatively affect the final yield (Downes, 1972; Gerik et al., 2003; McClure et al., 2010). Stages four and five occur when the last leaf (flag leaf) is visible and when all leaves have fully emerged and expanded. Stage six, or half bloom, occurs when half of the panicle has started to flower as the panicles start to flower from the top and progress downward (Poehlman, 1987; Vanderlip and Reeves, 1972). Stages seven and eight are the soft and hard dough stages, and the last stage is physiological maturity, which occurs when the plant has finished accumulating dry matter and maximum dry weight is achieved (Vanderlip and Reeves, 1972). The time that the grain sorghum plant will take to complete its entire life cycle largely depends on the maturity class of the hybrid and the growing conditions (Gerik et al., 2003).

\section{Adaptation, Production, and Uses}

Grain sorghum is adapted to many different regions and can grow in a wide range of growing conditions from temperate to tropical climates. It is well adapted to semi-arid regions such as eastern Colorado due to its drought tolerance (Jones and Johnson, 1991). The amount of water needed to produce an acceptable grain sorghum crop varies depending on the evapotranspiration rates in the area that the crop is grown (Kramer and Ross, 1970). The maturity class of the sorghum hybrid will also affect total water use during the growing season as longer-maturing hybrids can use more water (Cothren et al., 2000). De Wet and Harlan (1971) noted sorghum could be grown successfully in regions receiving between 380 and $1400 \mathrm{~mm}$ of annual rainfall. The optimal temperature for sorghum growth is generally between 33 and $37^{\circ} \mathrm{C}$, but this varies depending on the growth stage of the plant and on the heat or cold tolerance of a particular hybrid (Cothren et al, 2000; Peacock and Heinrich, 1984; Vinall and Reed, 1918). 
Sorghum will grow in a wide range of soil types from sandy to heavy clay soils, although in dry climates, soils with sand are desirable (Kramer and Ross, 1970). It is not tolerant of acid soils, but sorghum has moderate tolerance to saline soils and will grow in soils that range in $\mathrm{pH}$ from 5 to 8.3 , although the optimum pH range is 6.2 to 7.8 (Cothren et al., 2000). Nutrient requirements for grain sorghum are similar to corn, and in a growing season a sorghum grain crop yielding 6.3 metric tons ha ${ }^{-1}$ will use around 38,19 , and $10 \mathrm{~kg} \mathrm{ha}^{-1}$ of nitrogen, phosphorus, and potassium, respectively (Kramer and Ross, 1970; Whitney, 1998). Fertilizer amendments should be added based on soil test results and plant requirements, at planting or shortly thereafter for the most efficient utilization by the crop (Cothren et al., 2000).

Crop management practices for grain sorghum production vary widely depending on the production region; in low rainfall areas in the High Plains region of the United States, the main focus is on conserving soil moisture to help the crop reach its full yield potential. Hybrid selection is extremely important and they should be chosen from the latest maturity group that can be reliably grown in the region to help increase yield potential (Kramer and Ross, 1970; Martin et al., 2006; Roozeboom and Fjell, 1998). Other important characteristics to consider when selecting a hybrid are lodging, insect and disease resistance, cold tolerance, as well as the intended end-use of the grain where test weight, seed color, or feed values may be important (Cothren et al., 2000; Kramer and Ross, 1970; Roozeboom and Fjell, 1998).

In the High Plains region, grain sorghum is often included as part of a crop rotation with winter wheat preceding the sorghum crop, and a fallow period following sorghum (Kramer and Ross, 1970). The recommended planting date for grain sorghum is mainly based on soil moisture availability and the soil temperature at a $5 \mathrm{~cm}$ depth. In Colorado, it can be planted between mid-May and mid-June when soil temperatures rise above $10^{\circ} \mathrm{C}$ for three consecutive 
days and when no cool days are forecasted for the following seven to ten days. Seeding depths typically range between 2.5 and $7.5 \mathrm{~cm}$, and planting depths should be deep if soil moisture conditions at planting are dry and shallow if sufficient moisture for germination is available in the top $2 \mathrm{~cm}$ of the soil (Anda and Pinter, 1994; Cothren et al., 2000; Kramer and Ross, 1970).

Row spacings will depend on how the field will be cultivated for weed control after planting, planter equipment row spacing limitations, and moisture availability (Doggett, 1970; Kramer and Ross, 1970). Standard row spacings of $0.76 \mathrm{~m}$ may be used if cultivation is planned, but wider rows may be more appropriate if moisture is expected to be limited (Bond et al., 1964). Narrow rows are recommended if adequate moisture will be available during the growing season. The most common seeding rates for dryland production in the semi-arid High Plains range between 37,000 and 123,000 seeds per hectare, and they can be increased or decreased if more or less moisture is expected (Kramer and Ross, 1970). Broadleaf and grassy weeds can be controlled prior to planting using pre-emergent herbicides or tillage, and post-emergence herbicides can be used to control broadleaf weeds after emergence. Cultivation can also be used to control weeds later in the growing season, especially if herbicides are not an effective option (Kramer and Ross, 1970).

Insects that commonly infest grain sorghum crops during the growing season in the High Plains region include greenbugs and other aphids, earworms, armyworms, grasshoppers, spider mites, and the sorghum midge. One of the most damaging sorghum insects is the sorghum midge, which infests the panicle of the plant and can cause significant crop losses by feeding on developing grain (Brooks, 1998; McClure et al., 2010; Teetes and Pendleton, 2000). Sorghum midge infestations can be avoided or controlled by planting early maturing and resistant hybrids, controlling weeds such as johnsongrass, tilling the previous years' sorghum field residue, and by 
multiple insecticide applications during flowering (Teetes and Pendleton, 2000). Most insect infestations are controlled by incorporating integrated pest management practices or by applying insecticides, although chemical treatments may not be cost effective depending on the cost, number of applications, and current crop prices (Brooks, 1998). Major diseases of grain sorghum in the High Plains include stalk rots such as charcoal rot and anthracnose, pythium, and fusarium root rots (Frederiksen, 2000; McClure et al., 2010). Head smuts, maize dwarf mosaic virus, and bacterial and fungal foliar diseases such as bacterial stripe and sorghum downy mildew are also important sorghum diseases in the High Plains. According to Jardine (1998), the estimated annual crop loss from diseases in Kansas is about 5\%. Most of these diseases can be prevented by using resistant or tolerant hybrids and by adjusting cropping and management practices to help reduce the chance of the crop becoming infected (McClure et al., 2010).

Sorghum reaches physiological maturity when a visible black layer at the base of the kernel exists (Eastin et al., 1973). Grain sorghum is almost ready to harvest at this point, and the length of time between physiological maturity and harvest depends on the climate conditions. If grain-drying facilities are not available, the sorghum should be harvested when the kernel moisture has dropped to 14 percent or lower (Brandon et al., 1938; McClure et al., 2010). In the northern Great Plains region, a fall frost after the plants have reached maturity will kill the green foliage, and promote fast stalk and grain dry down for harvest. In the southern portion of the Great Plains, chemical harvest desiccants such as Diquat or Roundup Ultra may need to be used after physiological maturity has been reached to help the sorghum plants dry down faster in the field for timely harvest. Grain sorghum can be harvested using a combine equipped with a row crop header or a grain header, and attachments such as guards can be used to help reduce harvest losses from lodged plants (McClure et al., 2010). 
Grain sorghum has many different uses as a food and fuel source. In the United States, the major use of the crop is for livestock or poultry feeding since its composition is similar to corn (Lust et al., 2000; Martin et al., 2006). Sorghum has slightly higher protein levels and a lower fat content than corn, but its digestibility is usually lower than corn (Hale, 1970; Martin et al., 2006). A large portion of grain sorghum produced in the United States is exported to other countries for uses in the food industry (Lust et al., 2000; Martin et al., 2006). In the United States, grain not used as livestock feed gets used in the ethanol, food, brewing, and distilling industries. Approximately 30 to 35 percent of domestically produced grain sorghum is used for ethanol fuel production and ethanol could be a major market for producers in northeastern Colorado, along with local feedlots and birdseed companies. More recently, the domestic food industry has used grain sorghum as a wheat substitute in the gluten-free product market (Sorghum Checkoff, 2012).

\section{Sorghum and Corn Comparisons}

The major crop that competes with grain sorghum for dryland production acreage in the High Plains (including northeastern Colorado), is dryland corn. This is due to improvements in drought tolerance of corn in recent years and the ease of weed control with Roundup Ready corn (Stattenborg et al., 2008). Sorghum is better able to withstand drought conditions for longer periods of time than corn because of its extensive and deep fibrous root system, leaf rolling, and the ability of the stomata to recover more quickly after turgidity has been regained in the leaves (Doggett, 1970; Glover, 1959; Jones and Johnson, 1991; Kramer and Ross, 1970; Poehlman, 1987). Even though sorghum needs less water than corn over the course of the growing season to complete its life cycle, corn yield increases more per unit of water than sorghum (Norwood and Currie, 1997; Stone and Schlegel, 2006). 
Grain sorghum is more drought tolerant and can yield higher than corn in dry years, but in wet years corn usually performs better and has a greater potential for profitability (Norwood, 1999; Norwood and Currie, 1997; Poehlman, 1987; Stattenborg et al., 2008). Staggenborg et al. (2008) used historical grain sorghum and corn yield data from the Crop Performance Testing Programs in Nebraska and Kansas to calculate economic crossover points where sorghum would have a higher economic return than corn based on the crop prices and corn yield. They found that at a sorghum grain price that was $87 \%$ of the corn price, grain sorghum would have a higher

net return than corn, if the corn yield was $6.6 \mathrm{Mg} \mathrm{ha}^{-1}$ or lower. They also noted in the study that grain sorghum production costs were $\$ 78 \mathrm{ha}^{-1}$ lower than corn.

Controlling grass weeds in grain sorghum can be more challenging than in corn since there are no herbicide tolerant grain sorghum hybrids commercially available and there are no effective herbicides for grass control in sorghum after both have emerged (McClure et al., 2010). Grain sorghum can offer an advantage over corn for early season weed control as sorghum is planted two to four weeks after corn in the High Plains, which allows time for weeds to emerge and be controlled before the crop is planted (Leonard and Whitney, 1950). If weeds are not adequately controlled early on in the season, they will outcompete the grain sorghum for nutrients and water, therefore reducing yield as sorghum grows slowly during the first two to three growth stages (Stahlman and Wicks, 2000; Vanderlip, 1993).

\section{Measuring Maturity}

Physiological maturity in grain sorghum is reached when active dry matter accumulation finishes (McClure et al., 2010; Vanderlip and Reeves, 1972). Nutrients are no longer being translocated into the kernel and the dry down period starts at this point. Physiological maturity occurs prior to harvest maturity, which is reached when the grain has lost enough moisture to be 
easily threshed, usually around 14\% (Brandon et al., 1938). Grain sorghum kernels have a higher moisture content at physiological maturity than at harvest maturity, and moisture content at physiological maturity can vary between 25 and 35 percent depending on the growing conditions and the hybrid (Doggett, 1970; Vanderlip, 1993).

Different methods have been used to estimate physiological maturity in sorghum, such as the moisture content of the kernels, the date that maximum dry weight is achieved, or the date of an appearance of a black layer at the base of the kernels (Eastin et al., 1973). Maturity has also been measured using days after planting to half bloom, although this method has been shown to be unreliable for accurate estimation of physiological maturity due to different lengths of the grain-filling stage and different drying rates among years and hybrids. Moisture content measurements are not accurate estimators due to the large differences in moisture content of hybrids at physiological maturity (Warnes, 1963). By definition, the maximum dry weight date is the most accurate predictor of physiological maturity, but this method requires frequent sampling and drying of kernels, which is a very labor-intensive process. The date that the black layer becomes visible at the base of the kernel is another accurate predictor of physiological maturity since it corresponds with the cutoff of assimilates being translocated into the kernel. The black layer date is potentially as accurate as the maximum kernel dry weight method, and it is easier to measure since it can be observed in the field without the use of special tools (Eastin et al., 1973). Further, the black layer is commonly used to estimate physiological maturity in other crops such as corn.

The amount of time that it takes for a plant to complete its life cycle (from germination to physiological maturity) can be quantified using a thermal time system such as growing degreedays (Bruns, 2009; Wang, 1960). Other quantification methods such as days after planting to 
flowering or physiological maturity have been used, but the number of days to certain growth and development stages can vary widely depending on the environmental factors at different locations, which makes it unreliable for measuring maturity (Cross and Zuber, 1972; Gilmore and Rogers, 1958; Warnes 1963). The methodology behind tracking plant growth stages by using temperatures was initially done by Reaumur around 1730 (McMaster and Wilhelm, 1997; Wang, 1960). Modern thermal time systems have modified Reaumur's original heat-unit system.

The most common way to measure thermal time to maturity is by growing degree-days (GDD) where a specified base temperature is subtracted from the average daily air temperature (McMaster and Wilhelm, 1997; Wang, 1960). Typically, the average daily temperature is calculated from the maximum $\left(\mathrm{T}_{\max }\right)$ and minimum $\left(\mathrm{T}_{\min }\right)$ temperature over a 24-hour period (McMaster and Wilhelm, 1997) where: $G D D=\left[\left(T_{\max }+T_{\min }\right) / 2\right]-T_{\text {base }}$.

The base temperature $\left(\mathrm{T}_{\text {base }}\right)$ is the temperature below which development will not occur, and this temperature varies among crops and the plant growth stage. The daily GDD values are accumulated over the course of the growing season from the planting or emergence date (Gilmore and Rogers, 1958; McMaster and Wilhelm, 1997). Daily GDD (or cumulative) cannot be negative since development is halted when temperatures are below a certain threshold. Many different variations of the basic GDD equation exist, with different variations including maximum temperature thresholds (e.g. Cross and Zuber, 1972; Gilmore and Rogers, 1958).

The base temperature threshold that is commonly used for calculating GDD in grain sorghum usually ranges from 5 to $15^{\circ} \mathrm{C}$. Sorghum is sensitive to cold air temperatures during most developmental stages and cool temperatures can greatly inhibit growth and development of the plant (Ercoli et al., 2004; Staggenborg and Vanderlip, 1996). A study conducted by Ercoli et al. (2004) found that grain sorghum was able to grow at $8^{\circ} \mathrm{C}$, but at 2 and $5^{\circ} \mathrm{C}$, the plants stopped 
accumulating dry matter at the eight-leaf stage when they were tested at both short and long temperature durations. Arkin et al. (1976) used a base temperature of $5^{\circ} \mathrm{C}$ for their grain sorghum growth model and Huda (1988) used $7^{\circ} \mathrm{C}$ for his study that tested the validity of a sorghum growth simulation model. Gerik et al. (2003) used $7^{\circ} \mathrm{C}$ as their base temperature in a study simulating the seed number in grain sorghum using the growth model called Sorghum Growth Model-Kansas State and Texas (SORKAM). A base temperature of $5.7^{\circ} \mathrm{C}$ was used by Staggenborg and Vanderlip (2006) when they studied the effects of freezing temperatures on sorghum plants after anthesis. Grain sorghum handbooks and extension publications commonly use $10^{\circ} \mathrm{C}$ as a base temperature for calculating growing-degree days (Gerik et al., 2003; Neild and Smith, 1983; McClure et al., 2010).

Grain sorghum has a higher maximum temperature threshold than many other grass crops because of its $\mathrm{C}_{4}$ pathway for carbon dioxide fixation and plant anatomy (Downes, 1972; Hatch et al., 1967). The growing degree-day maximum temperature threshold for grain sorghum is not clearly defined and thresholds used by researchers differ greatly and range from 30 to $45^{\circ} \mathrm{C}$ (Craufurd and Qi, 2001; Norcio, 1976; Peacock and Heinrich, 1984). Few studies have been conducted to measure the photosynthetic capabilities of grain sorghum at different temperatures, and even fewer have been conducted in field environments (Muchow, 1990). A study by Norcio (1976) measured photosynthetic rates of two genotypes of grain sorghum at six different temperature regimes and two carbon dioxide concentrations. She found that photosynthetic rates were not significantly reduced until temperatures reached $43^{\circ} \mathrm{C}$. Photo-oxidation and a negative net photosynthetic rate occurred at $45^{\circ} \mathrm{C}$ for both hybrids at the two different carbon dioxide concentrations. The results from the study helped to indicate grain sorghum's maximum temperature threshold for development, which could be used when calculating GDD. Hammer et 
al. (1989) noted that the maximum temperature thresholds that were calculated based on temperature and development rate response curves for calculating growing degree-days were relatively unimportant. They found that varying maximum threshold values had little to no impact on the fit of their temperature responses as the maximum temperatures were well above temperatures recorded in the field during the study.

\section{Factors Affecting Maturity}

Past research has greatly increased our knowledge of the effects of agronomic and management practices on dryland grain sorghum yield in the semiarid High Plains, but little research has been done to investigate the effects of these factors on the thermal time to physiological maturity. Larson and Thompson (2011) studied the effects of planting populations on seed maturation on dryland trials in southeast Colorado and found that increasing the seeding rate of grain sorghum decreased the amount of time that it took for the grain to reach maturation. As plant populations are increased, fewer tillers are produced due to the increased plant competition and limiting resources during the vegetative growth stages (Lafarge et al., 2002; Larson and Thompson, 2011). In a plant population study done by Gerik and Neely (1987), a decreased number of tillers with increased plant populations shortened the overall maturity since the tillers flowered about seven to ten days later than the main culms. A similar effect on maturity was found by Bandaru et al. (2006) when they conducted a dryland study on growing sorghum in clumps, when plants grown in the clumps had fewer tillers and matured faster than plants grown in traditional rows.

Row spacing and orientation have been studied to find out if they play a role in sorghum maturity. Light interception by plants is affected by row direction and was found to be lower in rows planted east and west than in rows planted north and south (Steiner, 1986; Witt et al., 
1972). In a study done by Witt et al. (1972) in Manhattan, Kansas, light meters above and below the crop were used to determine the amount of light intercepted by the plants in the $300-450 \mathrm{~nm}$ range in the different treatments. Light interception by the plants was lower in the wide rows (1 $\mathrm{m}$ spacing) than in the narrow rows $(0.5 \mathrm{~m}$ spacing) in both row orientations. This was attributed to a decreased within row population from the row spacing, which allowed more light to be intercepted by the plants in the narrow rows. The light interception data was collected every five or seven days, beginning around mid-July. Up to $40 \%$ of the light reached the soil surface between the rows going north and south, helping to heat the surface. Less light reached the soil surface in the mid-point between the rows in the east/west orientation and more light on the south side of rows in the wide row spacing $(1 \mathrm{~m})$. At the same row spacing but north/south orientation, more light was accumulated at the mid-point than next to the rows. In a study using the SORKAM model, increasing row widths decreased the number of tillers due to within row plant densities increasing, which would shorten the time to maturity since fewer tillers were produced (Baumhardt et al., 2005).

Plant genetics and cultivar selection may have the biggest effect on the amount of thermal time that the plants take to reach full maturity (Croissant, 1969). Long season hybrids generally producer more tillers than short season hybrids, and the grain fill period is also extended in long season cultivars, both of which increase the total time to maturity (Baumhardt et al., 2005; Schaffer, 1980). Photoperiod during the growing season affects time to maturity as different sorghum hybrids have varying levels of photoperiod sensitivity. Photoperiod sensitive hybrids are more sensitive to temperature fluctuations than photoperiod insensitive hybrids, and will only flower when a certain photoperiod is reached during the growing season (Rooney and Aydin, 1999; Quinby and Schertz, 1970). 
Other important factors that affect the time to maturity are soil fertility, temperature, water availability, and solar radiation (Croissant, 1969; Roozeboom and Fjell, 1998; Vinall and Reed, 1918). When important macronutrients such as nitrogen and phosphorus are at adequate levels in the soil, maturity in sorghum can be hastened due to faster leaf development and more efficient photosynthetic capabilities of the plant (Srivastava and Singh, 1969). Cool temperatures can prolong the growth of the plant at all growth stages, as grain sorghum is very sensitive to cold temperatures during different development stages (Doggett, 1970). This is why a base temperature is used when calculating GDD for reaching development stages. Plants that are drought stressed will mature faster or slower depending on the growth stage of the plants, as drought will shorten the duration of grain filling, and will extend maturity if flowering has not occurred (Schaffer, 1980). A study by Vinall and Reed (1918), found that solar radiation intercepted by the plant was an important factor for the development rate of sorghum in addition to temperature, when they observed significant growth differences at two locations where the thermal time based on the air temperature was similar.

\section{Factors Affecting Yield}

Unlike maturity, much research has been done on the effects of agronomic factors on the overall yield of grain sorghum. Steiner (1986) found that high plant populations (18 compared to 6 and 12 plants $\mathrm{m}^{-2}$ ) decreased yield during dry years, and Wade and Douglas (1990) had similar results in their study when late maturing hybrids in high plant densities yielded much lower under water stress than when adequate water was available. In 1995, a study by Jones showed that yield in a dry year was higher in treatments with low plant populations and wide rows, than treatments with high populations and narrow rows. Bandaru et al. (2006) investigated the effects of growing sorghum plants in clumps as compared to the traditional $(75 \mathrm{~cm})$ row spacing to 
reduce vegetative growth (including tillers), and found that the yield was higher in the clump treatments since water was preserved early in the season, making more water available during flowering and grain filling. Tillers produced when water was limited did not increase or contribute to the overall final yield.

Bond et al. (1964) noted that sorghum grown in wide rows $(1 \mathrm{~m})$ yielded higher than when grown in narrow rows $(0.51 \mathrm{~m})$ during a drought year. Steiner (1986) also found that plants in wide rows used less water during the vegetative growth stage, and subsequently- more water was available later in the season during critical growth stages. Vigil et al. (2008) noted that the skip row yield was higher than traditional $0.76 \mathrm{~m}$ row spacings during years when moisture was limited and skip-row showed an advantage when the yield was lower than $3.5 \mathrm{Mg}$ ha $^{-1}$. Abunyewa et al. (2008) noted in a grain sorghum study in Nebraska that skip-row yield was increased when the yield in traditional row spacings were less than $4.5 \mathrm{Mg} \mathrm{ha}^{-1}$. Baumhardt et al. (2005) used the SORKAM crop model to simulate the dryland sorghum yield in Bushland, Texas from 1958 to 1998 , and observed that sorghum planted in narrow rows tillered more than in wide rows due to a lower within row population. Therefore, yield was higher in the narrow row spacings as more tillers were produced. Another dryland study conducted in the Texas High Plains concluded that row spacings of $1.5 \mathrm{~m}$ produced less grain than rows that were half as wide, and suggested using a lower seeding rate in the narrow rows to increase tillering and overall yield during wet years (Jones and Johnson, 1991). Stickler and Laude (1960) conducted a dryland study in Manhattan, Kansas and found no significant difference among row widths at a low seeding population, but as the population was increased, the yield increased in the narrow rows. 
Steiner's study in 1986 investigated the effects of row orientation on yield and found that row direction had no significant effects on yield or water consumption by the plants. In a light interception and yield study done by Witt et al. (1972), they saw no significant yield differences between two different row orientations of north/south and east/west planted rows. Lugg (1974) found that north and south oriented rows yielded higher than rows planted in the other three orientations of east/west, northwest/southeast, and northeast/southwest. He attributed the difference in yield mainly to differences in water availability and distribution within the trial area rather than to row orientation.

Late maturity hybrids tend to yield higher than shorter season sorghum hybrids due to the longer grain-filling period and increased vegetative growth (Baumhardt et al., 2005). Earlier maturing hybrids are generally more stable for yield than later maturing ones since the grainfilling period is shorter and less variable (Saeed and Francis, 1983). If the growing season is long enough, late maturity hybrids will almost always yield higher than early maturing hybrids, as long as both are well adapted for the growing conditions (Roozeboom and Fjell, 1998). If the growing season is short, late maturity hybrids will have a much higher chance of a reduced yield and test weight due to frost damage before physiological maturity (Staggenborg and Vanderlip, 1996).

Major environmental factors that can affect yield are water availability, soil fertility, and temperature. Yield can be negatively affected by water stress caused by prolonged drought conditions, especially during critical development stages such as flowering (Doggett, 1970; Kramer and Ross, 1970; Vanderlip, 1993). Adequate levels of important nutrients, such as nitrogen, phosphorus, and potassium ensure that the yield potential of hybrids is attainable, as more nutrients are needed as the yield potential increases (Cothren et al., 2000). Extreme high or 
low temperatures can negatively affect yield and excessively high temperatures before or during flowering can decrease the grain yield dramatically (Staggenborg and Vanderlip, 1996; Vanderlip, 1993; Vinall and Reed, 1918). Low temperatures can also decrease the yield during flowering, and low temperatures can be detrimental during the grain fill period when the plants are still accumulating dry matter (Staggenborg and Vanderlip, 1996). 


\section{REFERENCES}

Abunyewa, Akwai, Richard Ferguson, Charles Wortman, Drew Lyon, and Steve Mason.

"Sorghum Yield and Yield Components Under Different Skip-Row Configuration and Plant Density in Nebraska." Proceedings of the Great Plains Soil Fertility Conference. Denver, CO. Vol. 12. 2008. 94-100.

Anda, A., and L. Pinter. "Sorghum Germination and Development as Influenced by Soil Temperature and Water Content." Agronomy Journal 86.4 (1994): 621-24.

Arkin, G. F., R. L. Vanderlip, and J. T. Ritchie. "A Dynamic Grain Sorghum Growth Model." Transactions of the ASAE. Vol. 19. Saint Joseph: American Society of Agricultural Engineers, 1976. 622+.

Bandaru, Varaprasad, B. A. Stewart, R. L. Baumhardt, Satish Ambati, C. A. Robinson, and Alan Schlegel. "Growing Dryland Grain Sorghum in Clumps to Reduce Vegetative Growth and Increase Yield." Agronomy Journal 98.4 (2006): 1109-120.

Baumhardt, R. L., J. A. Tolk, and S. R. Winter. "Seeding Practices and Cultivar Maturity Effects on Simulated Dryland Grain Sorghum Yield." Agronomy Journal 97.3 (2005): 935-42.

Bond, J. J., T. J. Army, and O. R. Lehman. "Row Spacing, Plant Populations and Moisture Supply as Factors in Dryland Grain Sorghum Production." Agronomy Journal 56.1 (1964): 3-6. American Society of Agronomy. Accessed on 3 Feb. 2012.

Brandon, J. F., J. J. Curtis, and D. W. Robertson. "Harvesting." Sorghums in Colorado. Fort Collins: Colorado State College, Agricultural Experiment Station, 1938. 18-20.

Brooks, H. Leroy. "Major Sorghum Insects." Grain Sorghum Production Handbook. Manhattan, Kansas: Kansas State University, 1998. 21-23.

Bruns, H. Arnold. "A Survey of Factors Involved in Crop Maturity." Agronomy Journal 101.1 (2009): 60-66.

Cothren, J. T., J. E. Matocha, and L. E. Clark. "Integrated Crop Management for Sorghum." Sorghum: Origin, History, Technology, and Production. Ed. C. Wayne. Smith and Richard A. Frederiksen. New York: Wiley, 2000. 409-41.

Craufurd, P. Q., and Aiming M. Qi. "Photothermal Adaptation of Sorghum (Sorghum Bicolour) in Nigeria." Agricultural and Forest Meteorology 108.3 (2001): 199-211.

Croissant, Robert L. Environmental Effects on Crop Maturity. Thesis. Colorado State University, 1969. Fort Collins: Colorado State University, 1969. 
Cross, H. Z., and M. S. Zuber. "Prediction of Flowering Dates in Maize Based on Different Methods of Estimating Thermal Units." Agronomy Journal 64.3 (1972): 351-55.

Dahlberg, Jeff A. "Classification and Characterization of Sorghum." Sorghum: Origin, History, Technology, and Production. Ed. C. Wayne. Smith and Richard A. Frederiksen. New York: Wiley, 2000. 99-130.

De Wet, J. M. J. "Systematics and Evolution of Sorghum Sect. Sorghum (Gramineae)." American Journal of Botany 65.4 (1978): 477-84.

De Wet, J.M. J., and J. R. Harlan. "The Origin and Domestication of Sorghum Bicolor." Economic Botany 25.2 (1971): 128-35.

Dillon, Sally L., Frances M. Shapter, Robert J. Henry, Giovanni Cordeiro, Liz Izquierdo, and L. Slade Lee. "Domestication to Crop Improvement: Genetic Resources for Sorghum and Saccharum (Andropogoneae)." Annals of Botany 100.5 (2007): 975-89.

Doggett, Hugh. "Morphology and Reproduction." Sorghum. London: Longmans, 1970. 49-71.

Doggett, Hugh. "Physiology and Agronomy." Sorghum. London: Longmans, 1970. 180-211.

Doggett, Hugh. "The History, Origins and Classification of Sorghum." Sorghum. London: Longmans, 1970. 1-48.

Downes, R. W. "Effect of Temperature on the Phenology and Grain Yield of Sorghum Bicolor." Australian Journal of Agricultural Research 23.4 (1972): 585-94.

Eastin, Jerry D., Joe H. Hultquist, and C. Y. Sullivan. "Physiologic Maturity in Grain Sorghum." Crop Science 13.2 (1973): 175-78.

Ercoli, Laura, Marco Mariotti, Alessandro Masoni, and Iduna Arduini. "Growth Responses of Sorghum Plants to Chilling Temperature and Duration of Exposure." European Journal of Agronomy 21.1 (2004): 93-103. Science Direct. Accessed on 22 Jan. 2012.

Foreign Agriculture Service/United States Department of Agriculture. Office of Global Analysis. Grain: World Markets and Trade. Foreign Agriculture Service, Dec. 2011. Accessed on 28 Jan. 2012. <http://www.fas.usda.gov/psdonline/>.

Gerik, T. J., and C. L. Neely. "Plant Density Effects on Main Culm and Tiller Development of Grain Sorghum." Crop Science 27.6 (1987): 1225-230.

Gerik, Thomas J., Brent Bean, and Richard L. Vanderlip. Sorghum Growth and Development. College Station, Texas: Texas Cooperative Extension, Texas A \& M University System, 2003. 
Gilmore, Jr., E. C., and J. S. Rogers. "Heat Units as a Method of Measuring Maturity in Corn." Agronomy Journal 50.10 (1958): 611. American Society of Agronomy. Accessed on 1 Feb. 2012. <www.agronomy.org>.

Glover, J. "The Apparent Behaviour of Maize and Sorghum Stomata during and After Drought." The Journal of Agricultural Science 53.03 (1959): 412. Cambridge Journals. Accessed on 3 Feb. 2012.

Hale, William H. "Sorghum Grain in Ruminant Nutrition." Sorghum Production and Utilization. Ed. Joseph S. Wall and William M. Ross. Westport, CT: Avi Pub., 1970. 507-33.

Hammer, G. L., R. L. Vanderlip, G. Gibson, L. J. Wade, R. G. Henzell, D. R. Younger, J. Warren, and A. B. Dale. "Genotype-by-Environment Interaction in Grain Sorghum. II. Effects of Temperature and Photoperiod on Ontogeny." Crop Science 29.2 (1989): 37684.

Harlan, J. R., and J. M. J. De Wet. "A Simplified Classification of Cultivated Sorghum." Crop Science 12.2 (1972): 172-76.

Hatch, M. D., C. R. Slack, and Hilary S. Johnson. "Further Studies on a New Pathway of Photosynthetic Carbon Dioxide Fixation in Sugar-Cane and Its Occurrence in Other Plant Species." Biochemical Journal 102.2 (1967): 417-22. Biochemical Journal. Accessed on 10 Feb. 2012. <www.biochemj.org >.

Huda, A. K. S. "Simulating Growth and Yield Responses of Sorghum to Changes in Plant Density." Agronomy Journal 80.3 (1988): 541-47.

Jardine, Douglas. "Major Sorghum Diseases." Grain Sorghum Production Handbook. Manhattan, KS: Kansas State University, 1998. 18-20.

Jones, Ordie R., and Grant L. Johnson. "Row Width and Plant Density Effects on Texas High Plains Sorghum." Journal of Production Agriculture 4.4 (1991): 613-19.

Jones, Ordie R. Evaluation of a Short Season-High Density Production Strategy for Dryland Sorghum. Rep. no. 95-5. Bushland: Conservation and Production Research Laboratory, 1995.

Kramer, Nicholas W., and William M. Ross. "Cultivation of Grain Sorghum in the United States." Sorghum Production and Utilization. Ed. Joseph S. Wall and William M. Ross. Westport, CT: Avi Pub., 1970. 167-99.

Lafarge, T. A., I. J. Broad, and G. L. Hammer. "Tillering in Grain Sorghum Over a Wide Range of Population Densities: Identification of a Common Hierarchy for Tiller Emergence, Leaf Area Development and Fertility." Annals of Botany 90.1 (2002): 87-98. Annals of Botany. Oxford Journals. Accessed on 2 Feb. 2012. 
Larson, Kevin, and Dennis Thompson. "Dryland Grain Sorghum Seeding Rate and Seed Maturation, Brandon, 2010." Plainsman Research Center 2010 Research Reports (2011): 14-18.

Leonard, Warren H., and Robert S. Whitney. "Sorghums." Field Crops in Colorado. Minneapolis: Burgess Pub., 1950. 146-57.

Lugg, David G. Effect of Row Direction on Sorghum Production. Thesis. Colorado State University, 1974. Fort Collins: Colorado State University, 1974.

Lust, Tim, Dan O'Brien, G. A. Barnaby, Jr., and Mark Waller. "Marketing." Sorghum: Origin, History, Technology, and Production. Ed. C. Wayne. Smith and Richard A. Frederiksen. New York: Wiley, 2000. 591-646.

Martin, John H. "History and Classification of Sorghum." Sorghum Production and Utilization; Major Feed and Food Crops in Agriculture and Food Series. Ed. Joseph S. Wall and William M. Ross. Westport, CT: Avi Pub., 1970. 1-27.

Martin, John H., Richard P. Waldren, and David L. Stamp. "Sorghum." Principles of Field Crop Production. 4th ed. Upper Saddle River, New Jersey: Pearson Education, 2006. 341-66.

Maunder, A. B. "History of Cultivar Development in the United States: From "Memoirs of A. B. Maunder-Sorghum Breeder"' 1999. Sorghum: Origin, History, Technology, and Production. Ed. C. Wayne. Smith and Richard A. Frederiksen. New York: Wiley, 2000. 191-223.

McClure, Angela, Stephen Ebelhar, Chad Lee, Emerson Nafziger, and Terry Wyciskalla. High Plains Production Handbook. Ed. Jeff Dahlberg, Earl Roemer, Jeff Casten, Gary Kilgore, and James Vorderstrasse. Lubbock: United Sorghum Checkoff Program, 2010. High Plains Production Handbook. United Sorghum Checkoff Program. Accessed on 1 Feb. 2012.

McMaster, Gregory S., and W. W. Wilhelm. "Growing Degree-Days: One Equation, Two Interpretations." Agricultural and Forest Meteorology 87.4 (1997): 291-300.

Muchow, R. C. "Effect of High Temperature on the Rate and Duration of Grain Growth in FieldGrown Sorghum Bicolor (L.) Moench." Australian Journal of Agricultural Research 41.2 (1990): 329-37.

Neild, Ralph E., and D. T. Smith. G83-673 Maturity Dates and Freeze Risks Based on Growing Degree Days. 1983. University of Nebraska-Lincoln Extension. Accessed on 12 Jan. 2012. 
Norcio, Norma V. The Effects of High Temperatures and Moisture Stress on Photosynthetic and Respiration Rates of Grain Sorghum. Diss. University of Nebraska-Lincoln, 1976. ETD Collection for University of Nebraska-Lincoln. University of Nebraska-Lincoln. Accessed on 15 Jan. 2012. <http://digitalcommons.unl.edu/dissertations/AAI7714681/>.

Norwood, Charles A., and Randall S. Currie. "Dryland Corn vs. Grain Sorghum in Western Kansas." Journal of Production Agriculture 10.1 (1997): 152-56.

Norwood, Charles A. "Water Use and Yield of Dryland Row Crops as Affected by Tillage." Agronomy Journal 91.1 (1999): 108-15.

Peacock, J. M., and G. M. Heinrich. "Light and Temperature Responses in Sorghum." Agrometeorology of Sorghum and Millet in the Semi-Arid Tropics: Proceedings of the International Symposium, 15-20 Nov 1982, ICRISAT Center, India. Patancheru. Ed. S. M. Virmani, M.V. K. Sivakumar, and Vrinda Kumble. Andhra Pradesh: ICRISAT (International Crops Research Institute for the Semi-Arid Tropics), 1984. 143-58.

Poehlman, John M. "Breeding Sorghum and Millet." Breeding Field Crops. 3rd ed. Westport, CT: AVI Publ., 1987. 508-55.

Preface. Sorghum: Origin, History, Technology, and Production. Ed. C. Wayne. Smith and Richard A. Frederiksen. New York: Wiley, 2000.

Quinby, J. R., and R. E. Karper. "The Inheritance of 3 Genes That Influence Time of Floral Initiation and Maturity Date in Milo." Journal of the American Society of Agronomy 37.11 (1945): 916-36.

Quinby, J. Roy, and Keith F. Schertz. "Sorghum Genetics, Breeding, and Hybrid Seed Production." Sorghum Production and Utilization. Ed. Joseph S. Wall and William M. Ross. Westport, CT: Avi Pub., 1970. 73-117.

Rooney, William L., and Selahattin Aydin. "Genetic Control of a Photoperiod-Sensitive Response in Sorghum Bicolor (L.) Moench." Crop Science 39.2 (1999): 397-400. Accessed on 4 Feb. 2012.

Rooney, William R. "Genetics and Cytogenetics." Sorghum: Origin, History, Technology, and Production. Ed. C. Wayne. Smith and Richard A. Frederiksen. New York: Wiley, 2000. 261-307.

Roozeboom, Kraig, and Dale Fjell. "Selection of Grain Sorghum Hybrids." Grain Sorghum Production Handbook. Manhattan, Kansas: Kansas State University, 1998. 3-5.

Saeed, Mohammad, and C. A. Francis. "Yield Stability in Relation to Maturity in Grain Sorghum1." Crop Science 23.4 (1983): 683-87. 
Schaffer, James A. The Effect of Planting Date and Environment on the Phenology and Modeling of Grain Sorghum, Sorghum Bicolor (L.) Moench. Diss. Kansas State University, 1980. Manhattan: Kansas State University, 1980.

"Sorghum Market Development." Sorghum Checkoff. United Sorghum Checkoff Program, 2012. Accessed on 06 Feb. 2012. <http://www.sorghumcheckoff.com/sorghum-marketdevelopment>.

Srivastava, S. P., and Ambika Singh. "Maturity of Hybrid Sorghum as Influenced by Fertilizer Application and Intra-Row Spacings." Indian Journal of Agricultural Sciences 40.12 (1969): 1056-060.

Staggenborg, S. A., K. C. Dhuyvetter, and W. B. Gordon. "Grain Sorghum and Corn Comparisons: Yield, Economic, and Environmental Responses." Agronomy Journal 100.6 (2008): 1600-604. Accessed on 10 Nov. 2011.

Staggenborg, Scott A., and Richard L. Vanderlip. "Sorghum Grain Yield Reductions Caused by Duration and Timing of Freezing Temperatures." Agronomy Journal 88.3 (1996): 473-77.

Stahlman, Phillip W., and Gail A. Wicks. "Weeds and Their Control in Grain Sorghum." Sorghum: Origin, History, Technology, and Production. Ed. C. Wayne. Smith and Richard A. Frederiksen. New York: Wiley, 2000. 535-90.

Steiner, J. L. "Dryland Grain Sorghum Water Use, Light Interception, and Growth Responses to Planting Geometry." Agronomy Journal 78.4 (1986): 720-26.

Stickler, F. C., and H. H. Laude. "Effect of Row Spacing and Plant Population on Performance of Corn, Grain Sorghum and Forage Sorghum." Agronomy Journal 52.5 (1960): 275-77.

Stone, Loyd R., and Alan J. Schlegel. "Crop Water Use in Limited-Irrigation Environments." Kansas State University, 2006. Accessed on 9 Jan. 2012.

Teetes, George L., and Bonnie B. Pendleton. "Insect Pests of Sorghum." Sorghum: Origin, History, Technology, and Production. Ed. C. Wayne. Smith and Richard A. Frederiksen. New York: Wiley, 2000. 443-96.

United States Department of Agriculture. National Agricultural Statistics Service. U.S. and All States Data-Crops. National Agricultural Statistics Service. Accessed on 28 Jan. 2012.

Vanderlip, R. L., and H. E. Reeves. "Growth Stages of Sorghum [Sorghum Bicolor (L.) Moench]." Agronomy Journal 64.1 (1972): 13-16.

Vanderlip, Richard L. How a Sorghum Plant Develops. Manhattan: Kansas State University, 1993. 
Vigil, Merle F., W. B. Henry, F. J. Calderon, D. Poss, D. C. Nielsen, J. G. Benjamin, and Bob Klein. "A Use of Skip-Row Planting as a Strategy for Drought Mitigation in the West Central Great Plains." Proceedings of the Great Plains Soil Fertility Conference. Denver, CO. Vol. 12. 2008. 101-06.

Vinall, H. N., and H. R. Reed. "Effect of Temperature and Other Meteorological Factors on the Growth of Sorghums." Journal of Agricultural Research 13 (1918): 133-47.

Wade, L. J., and A. C. L. Douglas. "Effect of Plant Density on Grain Yield and Yield Stability of Sorghum Hybrids Differing in Maturity." Australian Journal of Experimental Agriculture 30 (1990): 257-64.

Wang, Jen Yu. "A Critique of the Heat Unit Approach to Plant Response Studies." Ecology 41.4 (1960): 785-90.

Warnes, Dennis D. "Comparison of Methods of Evaluating Relative Maturity in Grain Sorghum Hybrids." Agronomy Journal 55.6 (1963): 545-49. American Society of Agronomy. Accessed on 5 Feb. 2012.

Whitney, David. "Fertilizer Requirements." Grain Sorghum Production Handbook. Manhattan, Kansas: Kansas State University, 1998. 12-14.

Witt, Merle D., R. L. Vanderlip, and L. D. Bark. "Effect of Row Width and Orientation on Light Intercepted by Grain Sorghum." Transactions of the Kansas Academy of Science 75.1 (1972): 29-40. JSTOR. Accessed on 23 Jan. 2012. 


\section{CHAPTER 2: MANUSCRIPT}

\section{PROJECT SUMMARY}

Grain sorghum is an important dryland crop in southeast Colorado, but rarely grown in the northeast part of the state due to the short growing season. The goal of the study was to determine if dryland grain sorghum could consistently reach physiological maturity in the region by using agronomic practices and hybrid selection to hasten maturity. We hypothesized grain sorghum could be consistently grown in northeast Colorado and the probability of the sorghum reaching physiological maturity would be significantly affected by the use of different agronomic practices. The study investigated agronomic factors such as row orientation (north/south and east/west), seeding rate $\left(3,11\right.$, and 20 seeds $\left.\mathrm{m}^{-1}\right)$, and row spacing $(0.76$ and $1.5 \mathrm{~m})$, along with cultivar selection $(5745,88 \mathrm{P} 68$, and DKS29-28) within the early to medium-early maturity classes. The study was conducted in 2010 and 2011 at three locations in northeast Colorado for a total of four site years.

Growing degree-days (GDD) were used to quantify the amount of thermal time required for the sorghum treatments to reach physiological maturity. Results showed that hybrid selection and seeding rate treatments had a significant impact on the number of cumulative GDD required for the sorghum to reach physiological maturity. The growing environment and its interactions with hybrid and seeding rate treatments significantly affected maturity depending on moisture availability during the growing season. Grain yield was significantly affected by the growing environment, seeding rate, and hybrid selection. In wet environments, the high seeding rate yielded the most, while in dry environments, the yield was highest at the medium seeding rate. 
Overall probabilities of the hybrid treatments reaching maturity at Akron were high, while at Fort Collins, the probabilities were considerably lower depending on the GDD accumulation start date.

\section{INTRODUCTION}

Grain sorghum (Sorghum bicolor (L.) Moench) is an important dryland crop in southeast Colorado. Over 191,000 tonnes were produced in Colorado in 2010 (USDA, 2012). Grain sorghum is grown on few acres in northeast Colorado, as successful production is thought to be limited by the short growing season and cool night temperatures in the spring and fall. Ensuring that sorghum reaches physiological maturity before the first fall frost is vital, as a frost before physiological maturity can significantly reduce yield and test weight (Staggenborg and Vanderlip, 1996).

Many grain producers in northeast Colorado practice crop rotations that include winter wheat followed by a spring crop, and then a fallow period before planting back to winter wheat again (Kramer and Ross, 1970). Grain sorghum is an attractive crop for many producers due to its high adaptability to semi-arid regions and the relatively low cost of production compared to corn (Jones and Johnson, 1991; Staggenborg et al., 2008). Corn is the major crop competitor for dryland grain sorghum production in northeast Colorado due to the ease of weed control, ease of marketing, and improved drought tolerance in recent years (Staggenborg et al., 2008). Grain sorghum is more drought tolerant than corn and can yield higher than corn in dry years in Colorado when all other factors are held equal (Norwood, 1999; Staggenborg et al., 2008). 
During wet years, corn can out-yield sorghum and it therefore has a greater potential for profitability in regions with greater rainfall than eastern Colorado.

Previous research has increased our knowledge of the effects of agronomic practices on grain sorghum yield in the semi-arid High Plains, but little research has investigated the effects of these factors on the thermal time required for physiological maturity. The effect of planting population on seed maturation in dryland conditions was studied in southeast Colorado by Larson and Thompson in 2011. They found that increasing the seeding rate of grain sorghum decreased the amount of time required for grain maturation. As plant populations are increased, fewer tillers are produced due to the increased plant competition and limiting resources during the vegetative growth stages (Baumhardt et al., 2005; Lafarge et al., 2002; Larson and Thompson, 2011).

Different row spacings have been shown to significantly affect the number of tillers produced by plants, and thus affecting grain maturity by causing the main stem to mature later than if no tillers were produced. Field studies by Jones and Johnson (1991) and Staggenborg et al. (1999) have demonstrated that as row spacing is increased, the number of tillers decreases significantly due to the increased within-row plant competition, leading to earlier maturity. The effects of row orientation on maturity have not been studied directly, but Witt et al. (1972) determined the effects of row orientation on light interception, yield, and water use in grain sorghum. They concluded that row orientation did not significantly affect evapotranspiration or light interception by the plants, which suggests that row orientation would not have a significant impact on tillering or maturity since available plant resources would be unchanged.

Hybrid selection is one of the most important factors that can affect maturity since the amount of required GDD to maturity is mainly determined by genetics (Poehlman, 1987; Rooney 
and Aydin, 1999; Quinby and Karper, 1945). Hybrids in later maturity classes tend to tiller more than early maturity class hybrids, and the grain fill period is longer than in shorter season hybrids, which extends the total GDD to maturity (Baumhardt et al., 2005; Schaffer, 1980).

Unlike limited research on factors affecting sorghum maturity, much research has been conducted to study the effects of agronomic factors on the overall yield of grain sorghum. Jones (1995) found that yield in a dry year was higher in treatments with low plant populations and wide rows than in treatments with high populations and narrow rows. Bond et al. (1964) had similar results and noted that sorghum grown in wide rows $(1 \mathrm{~m})$ yielded higher than when it was grown in narrow rows $(.5 \mathrm{~m})$ during a drought year.

Steiner (1986) measured water use and plant growth for two row orientations, along with other treatments, at Bushland, TX. No significant yield differences were found between north/south and east/west row orientation. Steiner also reported that plants in wide rows used less water during the vegetative growth phase, and therefore more water was available during the reproductive phase.

Hybrid maturity has been known to affect yield since later maturing hybrids almost always yield higher than early maturing hybrids, when both are well adapted for the growing conditions and season length (Roozeboom and Fjell, 1998). If the growing season is short though, late maturity hybrids have a much higher chance of reduced yield and test weight due to frost occurring before physiological maturity is reached (Staggenborg and Vanderlip, 1996). Yield of earlier maturing hybrids is generally more stable than late maturing ones since the grain fill period is shorter and less variable (Saeed and Francis, 1983).

One of the main objectives of this research was to determine how multiple agronomic factors affect the amount of thermal time sorghum requires to reach physiological maturity. It 
was hypothesized that the factors investigated in the study (row spacing, row direction, planting population, and hybrid selection) would significantly affect the cumulative GDD it would take for the sorghum to reach maturity. This is important since maturity is the largest yield limiter in the northeast Colorado. Our second objective was to determine the probability of different cultivars reaching maturity at different locations in northeast Colorado based on maturity data collected during the study and long-term climate data. It was hypothesized that early maturity class grain sorghum would almost always reach maturity in northeast Colorado.

\section{MATERIALS AND METHODS}

\section{Site Descriptions}

The study was conducted in four different environments over two years in northeast Colorado. In 2010, trials were conducted at Stratton and Akron, and 2011 trials were conducted at Fort Collins and Akron. The trials at Akron in 2010 and 2011 were conducted at the USDA Central Great Plains Research Station. The elevation of the location is 1,384 meters. Akron has an average annual rainfall of $421 \mathrm{~mm}$ based on weather records from 1893 to 2011 (WRCC, 2012). The trial was planted on a Rago silt loam soil. The trial at Stratton in 2010 was conducted at the Colorado State University Dryland Agro-ecosystems Project site on a Richfield silty clay loam soil. The elevation of the Stratton site is 1325 meters and the average annual rainfall amount is $444 \mathrm{~mm}$ based on weather records from 1934 to 2011 (WRCC, 2012). The Fort Collins trial in 2011 was located on the Agricultural Research, Development and Education Center, at an elevation of 1,558 meters. The Fort Collins location has an average annual rainfall of $384 \mathrm{~mm}$ based weather records from 1893 to 2011 (WRCC, 2012). The soil at the Fort 
Collins trial was a Connerton-Barnum complex, which is a fine, sandy loam. All trials were rainfed, although the Fort Collins site had been irrigated in previous years.

\section{Study Design}

The study was conducted in 2010 and 2011. The north/south row oriented treatments included three cultivars (88P68, DKS29-28, and 5745), two row spacings (0.76 and $1.5 \mathrm{~m}$ ), and three seeding rates $\left(3,11\right.$, and 20 seeds $\left.\mathrm{m}^{-2}\right)$ for a total of 18 treatments. In the east/west row oriented treatments, a single seeding rate treatment of 11 seeds $\mathrm{m}^{-2}$ was used along with the two row spacing $(0.76$ and $1.5 \mathrm{~m})$ and three hybrid (88P68, DKS29-28, and 5745) treatments for a total of six treatments. The north/south row oriented treatments were planted at all four environments, while the east/west oriented treatments were planted at the Akron location in 2010 and 2011 (two environments).

Treatments within experiments were arranged in a split-plot design, with row spacing as the main plot, and the hybrid and planting density treatments as the sub-plots with four replications. Plot dimensions were $3 \mathrm{~m}$ wide by $9.1 \mathrm{~m}$ long and in the $0.76 \mathrm{~m}$ row width treatments, the two center rows of the four row plots were harvested ( $1.5 \mathrm{~m}$ wide) for yield. In the $1.5 \mathrm{~m}$ row spacing treatments, a single middle row was harvested for yield.

The three hybrids used in the study were selected from different seed companies to ensure a wide range of genetics. The $88 \mathrm{P} 68$ cultivar is an early maturity class hybrid from Pioneer Hi-Bred International, and has a semi-open panicle with red seeds. The DKS29-28 cultivar is an early maturing hybrid from Dekalb and exhibits a semi-open panicle with a bronze grain color. The 5745 hybrid from Syngenta is considered a medium-early maturing cultivar and has an open panicle with red grain. 
In 2010, the Akron trial was planted into no-till proso millet stubble on May 26 and harvested on October 28. Nitrogen was broadcast on May 27 at a rate of $44.8 \mathrm{~kg} \mathrm{ha}^{-1}$ and early season weeds were controlled with Lumax and Roundup herbicides before crop emergence. Weed infestations later in the growing season were controlled using 2, 4-D and hand weeding. The Stratton location was planted on June 4 into disked and mowed corn stubble, and harvested on November 4. Nitrogen was applied on June 6 at the same rate of $44.8 \mathrm{~kg} \mathrm{ha}^{-1}$. Glyphosate was used to control weeds before emergence and weed infestations later in the growing season were controlled by spot spraying using glyphosate, and hand weeding. No insect or disease infestations were noted for either trial location during the 2010 cropping season.

In 2011, the Akron trial was planted into no-till wheat stubble on June 6 and harvested on October 24. Nitrogen was broadcast on June 9 at a rate of $44.8 \mathrm{~kg} \mathrm{ha}^{-1}$ and early season weeds were controlled using Lumax herbicide before crop emergence. The Fort Collins location was planted on June 4 into tilled winter wheat stubble and harvested on November 11. Soil crusting occurred before crop emergence, so a rotary hoe was used after planting to promote better stand establishment. No fertilizer was applied and early season weeds were controlled using glyphosate. Weed infestations during the growing season were controlled using 2, 4-D and hand weeding. A three meter wide, four-row cone planter was used to plant all trials. At harvest, a modified Gleaner plot combine equipped with a Harvest Master grain weighing system was used to collect weight, grain moisture, and test weight data of each plot.

\section{Data Collection}

Physiological maturity was determined to be the date on which half of the kernels in half of the main stem in the plot had a visible black layer at the base of the kernel (Eastin et al., 1973). Seed samples for determining black layer (and maturity) were taken from three random 
plants in the plot where three to five kernels were pulled to determine if a black layer was present. Plot observations were made once every three days as plots were reaching physiological maturity. The thermal time from planting to physiological maturity was measured in thermal time expressed as GDD, with the accumulation of thermal time beginning at planting and concluding when the plants reached physiological maturity. The growing degree units for each daywere calculated as shown:

$$
\mathrm{GDD}=\left[\left(\mathrm{T}_{\max }+\mathrm{T}_{\min }\right) / 2\right]-\mathrm{T}_{\text {base }}
$$

Where $\mathrm{T}_{\max }$ and $\mathrm{T}_{\min }$ are the daily maximum and minimum temperature $\left({ }^{\circ} \mathrm{C}\right)$, respectively, and $\mathrm{T}_{\text {base }}$ is the base temperature $\left({ }^{\circ} \mathrm{C}\right)$. If the maximum daily temperature exceeds $45^{\circ} \mathrm{C}$ (Norcio, 1976), the maximum temperature is set to $45^{\circ} \mathrm{C}$. When the average daily temperature $\left(\mathrm{T}_{\max }+\right.$ $\left.\mathrm{T}_{\min }\right) / 2$ ) is below the base temperature $\left(\mathrm{T}_{\text {base }}\right)$ of $7^{\circ} \mathrm{C}$ (Ercoli et al., 2004; Gerik et al., 2003), no GDD are accumulated for that day.

Historical climate information from weather stations associated with the Colorado Climate Center, the Western Regional Climate Center (WRCC), and the USDA Akron Research Station were used to calculate the probability of the different hybrids to reach maturity before frost. Daily maximum and minimum temperatures from up to 100 available years were used to calculate long-term average GDD and average frost dates. The average frost date was defined as the date when there was a $50 \%$ probability of a freeze occurring on or before that date. A freeze was reached when the average minimum daily temperature was less than $-2^{\circ} \mathrm{C}$.

\section{Analysis}

The analysis of variance (ANOVA) was used in the MIXED procedure within the SAS program (SAS Institute, 2011). For maturity and yield measurement analyses, fixed effects in the model were environment, row spacing, hybrid, and seeding rate, along with all of their 
interactions. Random variables in the model were replicates within environment and the row spacing by replicate interaction within environments. Mean separation tests were done using the pdiff and slice options in SAS proc mixed. An alpha level of 0.05 was used to determine significant effects.

\section{RESULTS}

\section{Climate}

Trials were conducted in four different environments over two years. Growing conditions in 2010 were drier and warmer than the long-term average at both Stratton and Akron (Table 1). Stratton received higher than the long-term average amounts of rainfall during the warmest two months of the growing season (July and August), but below the long-term average rainfall in September and October. Akron received lower than the long-term average rainfall during most of the growing season with the total rainfall amount for the season being $95 \mathrm{~mm}$ lower than longterm average of $310 \mathrm{~mm}$. The sparse rainfall during the spring and summer resulted in severe drought conditions in late summer, especially at Akron. In 2011, the total rainfall was at, or above, the long-term average for both Akron and Fort Collins. Above average rainfall at both trial locations during the first half of the growing season prevented drought stress from minimal rainfall later in the season. Monthly average temperatures and cumulative GDD in 2011 were above the long-term average at both locations, especially during July and August.

\section{Maturity}

Experiment 1- Row Spacing, Hybrid, and Seeding rate for 2 Years in 4 Environments 
Table 2 provides the ANOVA results for the cumulative observed GDD and Table 3 shows the observed GDD for trial factors in four trial environments. Out of the four main effects and eleven interactions, only five were significant at a probability $\leq 0.05$ (Table 2). Significant effects (probability $\leq 0.05$ ) on maturity were observed for environment, hybrid, and seeding rate, as well as for the two-way interactions of environment by hybrid and environment by seeding rate. Among the main effects, row spacing was not significant.

The environment by hybrid two-way interaction for maturity in experiment one was significant. The 88P68 hybrid was significantly earlier than the DKS29-28 hybrid at both locations in 2010, however, in both locations in 2011, there was no significant difference between the cumulative observed GDD for the 88P68 and DKS29-28 hybrids (Figure 1). Significant differences were observed among hybrids within each environment (Table 3 ). The 5745 hybrid was significantly longer maturing than DKS29-28 and 88P68 at all four environments.

The environment by seeding rate two-way interaction was highly significant as the environmental effects greatly influenced the time to maturity among the three seeding rates (Figure 2). At Stratton (2010) and Fort Collins (2011), the lowest seeding rate (3 seeds $\mathrm{m}^{-2}$ ) took significantly longer to mature than the medium and low seeding rate treatments. The medium rate $\left(11\right.$ seeds $\left.\mathrm{m}^{-2}\right)$ took significantly longer to reach maturity than the high rate $\left(20\right.$ seeds $\left.\mathrm{m}^{-2}\right)$ at both locations. At Akron in 2011, the lowest seeding rate took significantly more GDD to reach maturity, but the medium seeding rate $\left(10\right.$ seeds $\left.\mathrm{m}^{-2}\right)$ took the least number of GDD to maturity instead of the high seeding rate, which was not expected. At Akron in 2010, there was no significant difference among any of the seeding rate treatments. In a combined ANOVA of Stratton (2010) and Fort Collins (2011), the interaction with seeding rates was not significant. In 
the significant seeding rate treatments from the combined ANOVA results, as the seeding rate was increased from 3 up to 20 seeds $\mathrm{m}^{-2}$, the average thermal time to maturity was decreased. The 3 seeds $\mathrm{m}^{-2}$ treatment took significantly more GDD (33) to reach maturity than planting 11 seeds $\mathrm{m}^{-2}$. The 11 seeds $\mathrm{m}^{-2}$ treatment took significantly more GDD (29) to mature than the seeding rate of 20 seeds $\mathrm{m}^{-2}$.

The hybrid and environment main effects were highly significant (Table 2). Among the hybrids, there was not a significant difference in the number of GDD to maturity between the two early maturity cultivars (88P68 and DKS29-28) but both matured significantly earlier than the medium-early maturity cultivar 5745 (Table 3). Hybrid 88P68 required 78 fewer GDD to reach maturity than hybrid 5745. Cumulative GDD to maturity at each of the environments were not significantly different from one another within years, but there was a significant difference across years. The sorghum reached maturity with 51 fewer GDD in the 2011 environments than in the 2010 environments (results not shown).

Experiment 2- Row Spacing, and Hybrid for 2 Years at Akron

Table 4 gives ANOVA results for the cumulative observed GDD to maturity in experiment 2 (east/west row oriented treatments) and Table 5 shows the observed GDD for trial factors in the two trial environments. Only hybrid and environment effects were significant at a probability $\leq 0.05$ (Table 4). Row spacing was not significant, and no interactions among main effects were significant. For the hybrid main effect, the medium-early cultivar (5745) required significantly more GDD (54) to reach maturity than the earlier maturing cultivar, DKS29-28 (Table 5). There was no significant difference in cumulative GDD to maturity between $88 \mathrm{P} 68$ and DKS29-28. For the environment main effect, significantly fewer GDD (48) were required for the treatments to reach maturity in the Akron 2011 than the 2010 environment. The 
experiment 2 (east/west row oriented treatments) main effect results were consistent with the experiment 1 (north/south row oriented treatments) main effects that were common between the two experiments.

Environment, Row Orientation, Row Spacing, and Hybrid in Experiments 1 and 2 at Akron

From results obtained in both experiments, certain trends were observed. Hybrid 5745

required more time to mature than the earlier maturing hybrids. In addition, earlier maturity was observed in 2011 than in 2010 at the Akron locations. Row spacing did not significantly affect maturity in either experiment. A trend for row orientation can be observed from comparing common treatments in experiment one (rows north/south) and experiment two (rows east/west). From this comparison, row orientation did not make a difference in thermal time to maturity. Long Term Predicted Probabilities of Hybrids Reaching Physiological Maturity at Akron and

\section{Fort Collins}

The probability of each hybrid reaching physiological maturity at the Akron and Fort Collins locations were compared (Table 6) using the 2011 experiment 1 (north/south row orientation treatments) GDD observations and long-term (100 years) daily temperature data from each location. At Akron, both of the early maturity class hybrids (88P68 and DKS29-28) have over an $80 \%$ probability of reaching physiological maturity before the average frost date of October 8 for all planting dates. The probability is based on GDD accumulation beginning on June 1, as producers in Colorado commonly plant grain sorghum on or before that date. The medium-early hybrid (5745) has a $62.5 \%$ chance of reaching physiological maturity at Akron before the average frost date based on the June 1 planting date (Table 6). The probabilities of reaching maturity are increased when the GDD accumulation start date is moved to May 23 (76 additional expected GDD) or May 15 (138 additional expected GDD) when compared to the 
June 1 date. Hybrids 88 P68 and DKS29-28 have over a 95\% chance of reaching maturity at Akron based on GDD accumulation starting on May 15 instead of June 1. The medium-early hybrid, 5745 , would have an $87.5 \%$ chance instead of a $62.5 \%$ chance if accumulation began on May 15 instead of June 1. In the Akron trials in 2010 and 2011, all hybrids and treatments reached physiological maturity before October 8 .

At Fort Collins, the probability of the hybrids reaching maturity is much lower due to a shorter growing season. The DKS29-28 and 88P68 hybrids would have a 38 and 36\% chance, respectively, of reaching maturity before the average frost date of October 9 based on GDD accumulation beginning on June 1 (Table 6). The 5745 cultivar would have a $15.5 \%$ chance of reaching full maturity at Fort Collins based on GDD accumulation beginning on June 1. The probabilities of reaching maturity are increased by at least $20 \%$ for each hybrid if GDD accumulation begins on May 23 instead of June 1. If GDD accumulation began on May 15, hybrids DKS29-28 and 88P68 would have a 73.5 and $70.8 \%$ chance of reaching maturity, respectively, while 5745 would have a $57.5 \%$ chance. In the Fort Collins environment during the 2011 study, all of the treatments (including the 5745 hybrid treatments) reached physiological maturity before the 2011 frost date of October 19, due to the unusually long growing season at Fort Collins during the 2011 trial year (Table 1).

\section{Yield}

Experiment 1- Row Spacing, Hybrid, and Seeding rate for 2 Years in 4 Environments

Table 7 shows the ANOVA results for grain yield and Table 8 shows the mean yield for trial factors in the four trial environments. Three of four main effects, and two out of eleven interactions were significant (Table 7). Significant factor effects on grain yield (probability $\leq$ 
0.05) were environment, hybrid, and seeding rate, as well as for the two-way interactions of environment by row spacing and environment by seeding rate. As observed with maturity date, the row spacing main effect on yield was not significant.

The significant environment by row spacing two-way interaction can be explained as different optimal row spacings in different environments. The grain yield at Fort Collins and Stratton was significantly higher in the $0.76 \mathrm{~m}$ row spacing than in the $1.5 \mathrm{~m}$ row spacing, but during both years at Akron, the yield was higher in the $1.5 \mathrm{~m}$ row spacing (Table 8). The $1.5 \mathrm{~m}$ row spacing was significantly superior to the $0.76 \mathrm{~m}$ row spacing at Akron in 2010, but they were not significantly different in 2011. The environment by seeding rate interaction for yield was also highly significant. There was a significant difference in yield at the Fort Collins environment since the 3 seeds $\mathrm{m}^{-2}$ seeding rate yielded 1,846 $\mathrm{kg} \mathrm{ha}^{-1}$ lower than the next highest yielding seeding rate of 11 seeds $\mathrm{m}^{-2}$. The grain yield differences among seeding rates were not significant at any of the other environments.

The seeding rate, hybrid, and environment main effects were all significant (probability $\leq$ 0.05). The seeding rate effect was significant due to the low seeding rate treatment $\left(3\right.$ seeds $\left.\mathrm{m}^{-2}\right)$ yielding significantly lower than both the medium and high seeding rate treatments (11 and 20 seeds $\mathrm{m}^{-2}$ ) (Table 8 ). The hybrid main effect was significant as the $88 \mathrm{P} 68$ hybrid yielded significantly lower than DKS29-28 and 5745 hybrids. There was no significant difference in yield between the DKS29-28 and the 5745 hybrids. The environment main effect significantly affected the overall trial yield, with the 2010 Akron trial yielding significantly lower than the other three environments. The Fort Collins yield was significantly higher than the other three trials, with $1850 \mathrm{~kg} \mathrm{ha}^{-1}$ more grain produced at Fort Collins than the next highest yielding 
environment at Akron in 2011. The 2011 Akron and the 2010 Stratton environment yields were not significantly different from each other.

Environment, Row Orientation, Row Spacing, and Hybrid in Experiments 1 and 2 at Akron

Experiment 2 (east/west row oriented treatments) results for Akron in 2010 were not available and therefore not included in the results. Grain yield results at Akron in 2011 showed no significant difference between the two row spacings, or among hybrids. No interactions were significant (results not shown). Row spacing was not a significant factor on yield in either experiment. Two trends were noted when comparing the yield from common treatments in experiments one and two at Akron in 2011. The 88P68 hybrid yielded substantially less than DKS29-28 and 5745 in both row orientations. From the average grain yield for treatments common to both trials, the east/west orientation (experiment 2) was higher yielding by $525 \mathrm{~kg} \mathrm{ha}^{-}$

${ }^{1}$ than the north/south orientation (experiment 1) (results not shown).

\section{DISCUSSION}

\section{Maturity}

The trial environment, hybrid, and seeding rate main factors, and the interaction of environment with hybrid and environment with seeding rate, significantly affected the cumulative GDD required for maturity. The interaction between the seeding rate and the four trial environments on cumulative GDD to maturity occurred due to different effect trends at Akron in 2010 and 2011 compared to Stratton in 2010 and Fort Collins in 2011. The seeding rate main effect results at Stratton in 2010 and Fort Collins 2011 were expected. As planting populations are increased, the number of tillers per plant is generally decreased since plant 
competition is greater (Baumhardt et al., 2005; Lafarge et al., 2002). These trial results are consistent with previously published studies, where the high seeding rate treatment matured earlier than the low seeding rate treatment (largest difference was 72 GDD at Stratton). At Akron in 2010, the population effect was most likely not significant due to water stress from July through September, which caused the different planting population treatments to mature about the same time. Plant stands early in the season were at acceptable levels in all of the seeding rate treatments. At Akron in 2011, the low seeding rate took significantly more GDD to reach maturity than the medium and high seeding rates.

Based on the relationship of population to tillering, the wide row spacing should have decreased the cumulative GDD to maturity, since the within-row populations are increased and tillering is decreased. The overall plant emergence and stands in the skip-row treatments $(1.5 \mathrm{~m}$ widths) were not any lower than the stands in the $.56 \mathrm{~m}$ row widths. We do not know why, but the row spacing effect may not have significantly affected maturity in this study since sufficient amounts of available water between the wide rows could have offset the effect of the increased competition within the rows. Results from a sorghum study by Jones and Johnson (1991), showed that plant tillering in a narrow row spacing $(0.76 \mathrm{~m})$ was significantly higher than in the wide $(1.5 \mathrm{~m})$ row spacing during every year of their three year study, which was also found in a study by Staggenborg et al. (1999). Their results suggest that the cumulative GDD to maturity in the narrow rows would be higher than in the skip-rows due to the increased tillering.

Hybrids in different maturity classes will reach physiological maturity at different times due to genetic differences, which was confirmed in this study (Poehlman, 1987; Rooney and Aydin, 1999; Quinby and Karper, 1945). The hybrid in the medium-early maturity class took significantly more time to reach maturity than the two hybrids in the early maturity class at all of 
the trial environments. Hybrid selection should begin with selecting hybrids in the appropriate maturity class based on the length of the growing season.

Due to field design limitations, it was not possible to include randomized row orientation treatments within the experiments, although general comparisons between experiments one and two did not show a trend in the difference in maturity when comparing the row orientations. Another study investigated the effects of row orientation on light interception and water use of sorghum have also found row orientation did not affect light interception by plants (Witt et al., 1972), which would suggest that row orientation would not have an impact on maturity.

Of the two trial locations, Fort Collins has a shorter average growing season than Akron. In 2011, the length of the growing season at Fort Collins was unusually long and the fall frost date occurred 10 days later than the expected average date based on 100-year weather records. At Akron, an early maturing variety would have a high chance of reaching physiological maturity before the first fall frost at any of the three GDD accumulation start dates from May 15 to June 1 . The medium-early maturity variety would have an acceptable chance (62.5\%) of reaching physiological maturity at Akron based on the June 1 GDD accumulation start date, but the probability could be greatly increased if accumulation began on May $23(81.5 \%)$ or on May $15(87.5 \%)$. If two cultivars within the same maturity class take about the same amount of time to reach physiological maturity (such as the two early maturity hybrids in the study), other hybrid characteristics such as yield or stalk strength should be taken into consideration as criteria for hybrid selection. At Fort Collins, the early maturing cultivars are not expected to reach maturity over $60 \%$ of the time, while the medium-early hybrid only has a $15.5 \%$ chance of reaching maturity based on a June 1 GDD accumulation start date. 
The probabilities of reaching maturity could be significantly increased by planting earlier in the season so more GDD will be accumulated over the course of the entire growing season. Based on the results, if the 5745 cultivar was planted on May 15 at Fort Collins instead of June 1, the probability of reaching maturity before the frost date of October 9 would increase from 15.5 to $57.5 \%$. The probability of a hybrid reaching physiological maturity at a location similar to Akron or Fort Collins can be increased by planting earlier in the growing season when soil temperature and moisture are conducive for seedling emergence and growth. The effect of the planting date on the probability of reaching maturity is just as important as choosing an appropriate hybrid in the correct maturity class. If sorghum can be planted earlier, a later maturing hybrid could be used to increase potential grain yield since more GDD units will be accumulated during the growing season.

\section{Yield}

The trial yield was significantly affected by row spacing at three of the four environments. In the dry environment at Akron in 2010, the wide/skip-row (1.5 m) treatment yielded higher than the narrow row treatment. In the normal to wet environments at Stratton and Fort Collins, yield was higher in the narrow row spacing treatments. Similar results were reported by Bond et al. (1964), as wide row spacing treatments in their study yielded higher than narrow rows when less than $13 \mathrm{~cm}$ of moisture was available in the soil profile. Vigil et al. (2008) also found skip-row yield was higher in traditional $0.76 \mathrm{~m}$ row spacings during years when moisture was limited.

The seeding rate by environment interaction was highly significant for yield. At Fort Collins and Stratton, yield increased as the seeding rate increased due to ample soil moisture during the growing season. The yield at Fort Collins was particularly high for dryland 
production, which was attributed to a high amount of available soil moisture since the trial site was irrigated in previous years. During both trial years at Akron, the medium seeding rate (11 seeds $\mathrm{m}^{-2}$ ) had the highest yield of the three seeding rate treatments. At the highest seeding rate $\left(20\right.$ seeds $\left.\mathrm{m}^{-2}\right)$, the yield was similar to the yield of the lowest seeding rate $\left(3\right.$ seeds $\left.\mathrm{m}^{-2}\right)$. In a dryland sorghum study by Steiner (1986) he concluded that a seeding rate of 18 plants $\mathrm{m}^{-2}$ was lower yielding than seeding rates of 6 or 12 plants $\mathrm{m}^{-2}$.

\section{CONCLUSIONS}

The results of the study showed that seeding rates, hybrid selection, and planting dates can be important factors to consider when trying to ensure grain sorghum will reach physiological maturity at a location before the average frost date. Our hypothesis that the agronomic factors would have a significant impact on the cumulative GDD to maturity was partially correct since seeding rate and hybrid main effects were significant. In general, as seeding rates were increased, the cumulative GDD to maturity was shortened for all of the hybrids, but the yield was highest for the medium $\left(11\right.$ seeds $\left.\mathrm{m}^{-1}\right)$ seeding rate. Hybrid selection should mainly be based on cultivar maturity, followed by selecting hybrids within the class that are high yielding and have specific characteristics that are important to the producer depending on growing conditions. Grain sorghum should be planted as early in the season as possible to increase the probability of reaching physiological maturity, as planting even seven days earlier can substantially increase the probability of a hybrid reaching maturity.

Our second objective was to determine the probability of different cultivars reaching maturity at different locations in northeast Colorado based on maturity data collected during the 
study and long-term climate data. It was hypothesized that early maturity class grain sorghum would almost always reach maturity in northeast Colorado.

Our hypothesis that early maturing grain sorghum would have a high probability of reaching physiological maturity in northeast Colorado was confirmed for the Akron location, but at Fort Collins all the probabilities were below 73.5\%. Akron is more representative of large portions of northeast Colorado where dryland crops are predominate. We found that earlier maturity cultivars can be produced at Akron with reasonable confidence (minimum probability was $81 \%$ for the early maturity hybrids and $62.5 \%$ for the medium-early hybrid) they will reach physiological maturity before the first freeze based on three different GDD accumulation start dates. At a location with an even shorter growing season than Akron, such as Fort Collins, only early maturing cultivars should be grown, and grain sorghum should be planted as early as possible. 


\section{TABLES}

Table 1. Long-term average (avg.) and trial monthly rainfall, temperature (temp.), and growing degree-day (GDD) data during the growing season at the four trial environments.

\begin{tabular}{|c|c|c|c|c|c|c|}
\hline Month & Trial Rainfall & $\begin{array}{l}\text { Long-term avg. } \\
\text { rainfall } \uparrow\end{array}$ & $\begin{array}{l}\text { Trial avg. maximum I } \\
\text { temp. }\end{array}$ & $\begin{array}{c}\text { Long-term avg. } \\
\text { temp. } \dagger\end{array}$ & Trial avg. GDD & $\begin{array}{c}\text { Long-term avg. } \\
\text { GDD†t }\end{array}$ \\
\hline \multicolumn{7}{|c|}{ Stratton, CO, 2010} \\
\hline May & 46 & 69 & 19.8 & 14.9 & & \\
\hline June & 17 & 64 & 29.3 & 20.6 & 411 & 401 \\
\hline July & 132 & 75 & 31.7 & 24.1 & 508 & 522 \\
\hline Aug. & 85 & 63 & 31.9 & 23.1 & 496 & 492 \\
\hline Sept. & 7 & 33 & 28.7 & 18.1 & 346 & 328 \\
\hline Oct. & 7 & 28 & 21.0 & 11.7 & 144 & 160 \\
\hline Sum & 295 & 331 & & & 1905 & 1903 \\
\hline \multicolumn{7}{|c|}{$\underline{\text { Akron, } \mathrm{CO}, 2010}$} \\
\hline May & 43 & 74 & 20.1 & 13.4 & & \\
\hline June & 59 & 59 & 28.3 & 19.4 & 395 & 368 \\
\hline July & 47 & 66 & 31.4 & 23.3 & 491 & 501 \\
\hline Aug. & 43 & 58 & 31.5 & 21.9 & 491 & 466 \\
\hline Sept. & 4 & 31 & 28.5 & 17.1 & 340 & 300 \\
\hline Oct. & 17 & 23 & 20.6 & 10.1 & 154 & 133 \\
\hline Sum & 215 & 310 & & & 1871 & 1767 \\
\hline \multicolumn{7}{|c|}{$\underline{\text { Akron, } \mathrm{CO}, 2011}$} \\
\hline May & 163 & 74 & 18.7 & 13.4 & & \\
\hline June & 36 & 59 & 28.0 & 19.4 & 372 & 368 \\
\hline July & 104 & 66 & 32.6 & 23.3 & 529 & 501 \\
\hline Aug. & 2 & 58 & 33.3 & 21.9 & 533 & 466 \\
\hline Sept. & 31 & 31 & 25.0 & 17.1 & 287 & 300 \\
\hline Oct. & 26 & 23 & 18.4 & 10.1 & 133 & 133 \\
\hline Sum & 362 & 310 & & & 1854 & 1767 \\
\hline \multicolumn{7}{|c|}{ Fort Collins, CO, 2011} \\
\hline May & 90 & 70 & 17.4 & 13.1 & & \\
\hline June & 51 & 47 & 27.3 & 18.2 & 344 & 343 \\
\hline July & 46 & 41 & 31.3 & 21.4 & 487 & 456 \\
\hline Aug. & 6 & 36 & 31.8 & 20.4 & 479 & 421 \\
\hline Sept. & 24 & 32 & 24.6 & 15.7 & 268 & 266 \\
\hline Oct. & 38 & 29 & 18.7 & 9.6 & 117 & 108 \\
\hline Sum & 255 & 254 & & & 1695 & 1594 \\
\hline
\end{tabular}


Table 2. ANOVA results of cumulative growing degree-days to maturity for three seeding rate, three hybrid, two row spacing, and four environments in 2010 and 2011 in the north/south row orientation.

\begin{tabular}{lcc}
\hline Effect & df & P $>$ F \\
\hline Environment (ENV) & 3 & 0.010 \\
Row Spacing (RS) & 1 & 0.830 \\
Hybrid (H) & 2 & $<0.001$ \\
Seeding rate (PR) & 2 & $<0.001$ \\
ENV X RS & 3 & 0.568 \\
ENV X H & 6 & 0.003 \\
ENV X PR & 6 & $<0.001$ \\
RS X H & 2 & 0.053 \\
RS X PR & 2 & 0.158 \\
H X PR & 4 & 0.441 \\
ENV X RS X H & 6 & 0.064 \\
ENV X RS X PR & 6 & 0.139 \\
ENV X H X PR & 12 & 0.886 \\
RS X H X PR & 4 & 0.294 \\
ENV X RS X H X PR & 12 & 0.081 \\
\hline
\end{tabular}

Table 3. Cumulative growing degree-days (GDD) from planting to maturity for two row widths, three seeding rates, and three hybrids over four trial environments in the north/south row orientation.

\begin{tabular}{|c|c|c|c|c|c|c|c|}
\hline \multirow[b]{2}{*}{ Main Effect } & \multicolumn{3}{|c|}{ Hybrid } & \multicolumn{3}{|c|}{ Seeding Rate, seeds $\mathrm{m}^{-2}$} & \multirow[b]{2}{*}{$\begin{array}{c}\text { Overall } \\
\text { Average }\end{array}$} \\
\hline & 88Р68 & DKS29-28 & 5745 & 4,050 & 18,200 & 32,400 & \\
\hline Row spacing, $m$ & & & 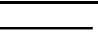 & \multicolumn{3}{|c|}{ cumulative GDD } & \\
\hline 0.76 & 1609 & 1612 & 1681 & 1651 & 1632 & 1618 & 1633 \\
\hline 1.5 & 1586 & 1614 & 1671 & 1649 & 1617 & 1605 & 1623 \\
\hline \multicolumn{8}{|l|}{ Environment } \\
\hline Stratton (2010) & 1611 & 1659 & 1699 & 1694 & 1659 & 1622 & 1656 \\
\hline Akron (2010) & 1617 & 1644 & 1709 & 1648 & 1660 & 1660 & 1656 \\
\hline Akron (2011) & 1582 & 1579 & 1654 & 1637 & 1588 & 1591 & 1605 \\
\hline Fort Collins (2011) & 1584 & 1580 & 1650 & 1636 & 1601 & 1576 & 1605 \\
\hline Overall Average & 1598 & 1613 & 1676 & 1650 & 1625 & 1611 & 1629 \\
\hline
\end{tabular}


Table 4. ANOVA results of cumulative growing degree-days to maturity for two environment, two row spacing, and three hybrid treatments in the east/west row orientation.

\begin{tabular}{lcc}
\hline \multicolumn{1}{c}{ Effect } & df & P $>$ F \\
\hline Environment (ENV) & 1 & 0.005 \\
Row Spacing (RS) & 1 & 0.901 \\
Hybrid (H) & 2 & $<0.001$ \\
ENV X RS & 1 & 0.425 \\
ENV X H & 2 & 0.082 \\
RS X H & 2 & 0.824 \\
ENV X RS X H & 2 & 0.114 \\
\hline
\end{tabular}

Table 5. Cumulative growing degree-days (GDD) from planting to maturity for two row widths and three hybrids in two environments in the east/west row orientation.

\begin{tabular}{lcccc}
\hline & \multicolumn{3}{c}{ Hybrid } & \\
\cline { 2 - 5 } \multicolumn{1}{c}{ Effect } & $88 P 68$ & DKS29-28 & 5745 & $\begin{array}{c}\text { Overall } \\
\text { Average }\end{array}$ \\
\cline { 2 - 5 } & Row spacing, $m$ & & cumulative GDD & \\
\cline { 3 - 5 } 0.76 & 1598 & 1608 & 1659 & 1622 \\
1.5 & 1600 & 1603 & 1660 & 1621 \\
Environment & & & & \\
Akron (2010) & 1616 & 1637 & 1682 & 1645 \\
Akron (2011) & 1582 & 1573 & 1636 & 1597 \\
& & & & \\
Overall average & 1599 & 1605 & 1659 & 1621 \\
\hline
\end{tabular}


Table 6. Expected probability of hybrids reaching physiological maturity at two locations based on 2011 growing degree-days (GDD) to maturity from three start dates to the average freeze date. $\uparrow$

\begin{tabular}{llccc}
\hline \multirow{2}{*}{ Location } & Hybrid & \multicolumn{3}{c}{ GDD Accumulation Start Date } \\
\cline { 3 - 4 } Akron & & May 15 & May 23 & June 1 \\
\cline { 3 - 4 } & DKS29-28 & 97.0 & percent & \\
\cline { 3 - 5 } & 88P68 & 96.5 & 90.5 & 81.0 \\
& 5745 & 87.5 & 81.5 & 62.5
\end{tabular}

Fort Collins

\begin{tabular}{llll} 
DKS29-28 & 73.5 & 58.0 & 38.0 \\
88 P68 & 70.8 & 57.5 & 36.0 \\
5745 & 57.5 & 38.0 & 15.5 \\
\hline
\end{tabular}

$\dagger$ Long-term average freeze dates are mean dates (Oct. 8 at Akron and Oct. 9 at Ft. Collins) when average minimum temperatures are expected to be less than $-2^{\circ} \mathrm{C}$ based on data from 1912 to 2011 at Akron and Fort Collins.

Table 7. ANOVA results of grain yield for four environment, two row spacing, three hybrid, and three seeding rate treatments in the north/south row orientation.

\begin{tabular}{lcc}
\hline Effect & df & P $>$ F \\
\hline Environment (ENV) & 3 & $<0.001$ \\
Row Spacing (RS) & 1 & 0.163 \\
Hybrid (H) & 2 & 0.031 \\
Seeding rate (PR) & 2 & $<0.001$ \\
ENV X RS & 3 & 0.002 \\
ENV X H & 6 & 0.273 \\
ENV X PR & 6 & $<0.001$ \\
RS X H & 2 & 0.745 \\
RS X PR & 2 & 0.364 \\
H X PR & 4 & 0.537 \\
ENV X RS X H & 6 & 0.104 \\
ENV X RS X PR & 6 & 0.200 \\
ENV X H X PR & 12 & 0.678 \\
RS X H X PR & 4 & 0.990 \\
ENV X RS X H X PR & 12 & 0.973 \\
\hline
\end{tabular}


Table 8. Grain yield results for two row spacings, three seeding rates, and three hybrids across four environments in the north/south row orientation.

\begin{tabular}{|c|c|c|c|c|c|c|c|c|}
\hline \multirow[b]{2}{*}{ Main Effect } & \multicolumn{3}{|c|}{ Hybrid } & \multicolumn{4}{|c|}{ Environment } & \multirow[b]{2}{*}{$\begin{array}{r}\text { Overall } \\
\text { Average }\end{array}$} \\
\hline & $88 \mathrm{P} 68$ & DKS29-28 & 5745 & $\begin{array}{c}\text { Stratton } \\
(2010) \\
\end{array}$ & $\begin{array}{l}\text { Akron } \\
(2010) \\
\end{array}$ & $\begin{array}{l}\text { Akron } \\
(2011) \\
\end{array}$ & $\begin{array}{c}\text { Fort Collins } \\
(2011)\end{array}$ & \\
\hline Row spacing, $\mathrm{m}$ & \multicolumn{8}{|c|}{$\mathrm{kg} \mathrm{ha}^{-1}$} \\
\hline 0.76 & 2862 & 3290 & 3147 & 2961 & 1298 & 2927 & 5213 & 3100 \\
\hline 1.5 & 2771 & 3000 & 2903 & 1995 & 2083 & 3062 & 4467 & 2891 \\
\hline \multicolumn{9}{|c|}{$\underline{\text { Seeding rate, seeds } \mathrm{m}^{-2}}$} \\
\hline 3 & 2410 & 2530 & 2652 & 2192 & 1514 & 2902 & 3559 & 2531 \\
\hline 11 & 3143 & 3384 & 3192 & 2548 & 1882 & 3123 & 5404 & 3239 \\
\hline 20 & 2895 & 3507 & 3232 & 2692 & 1675 & 2959 & 5518 & 3211 \\
\hline Overall Average & 2816 & 3147 & 3025 & 2478 & 1690 & 2995 & 4845 & 2995 \\
\hline
\end{tabular}




\section{FIGURES}

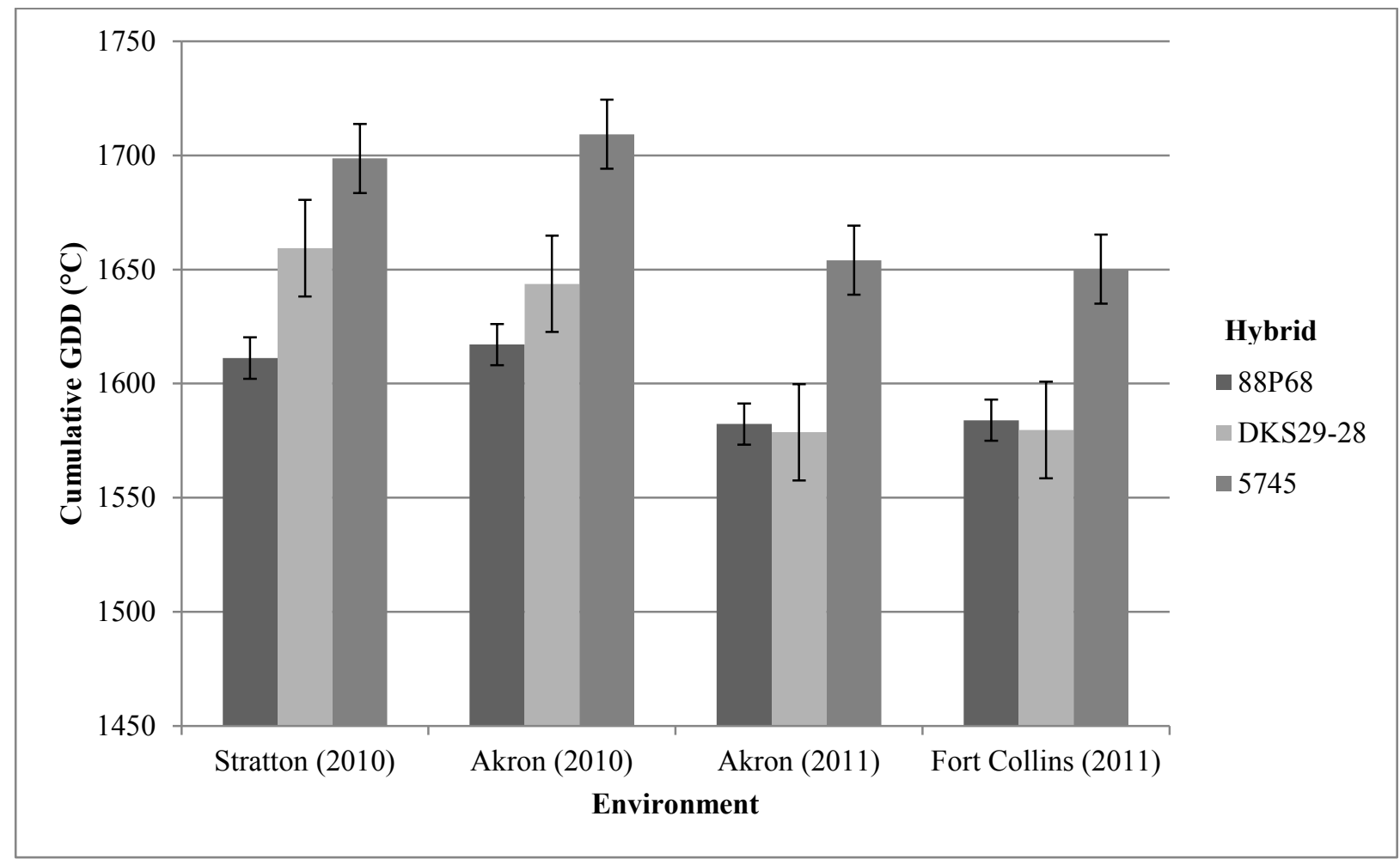

Figure 1. Cumulative growing degree-days from planting to physiological maturity for three hybrids within environments in the north/south row orientation (experiment 1). All treatments within a location are pooled within an environment. 


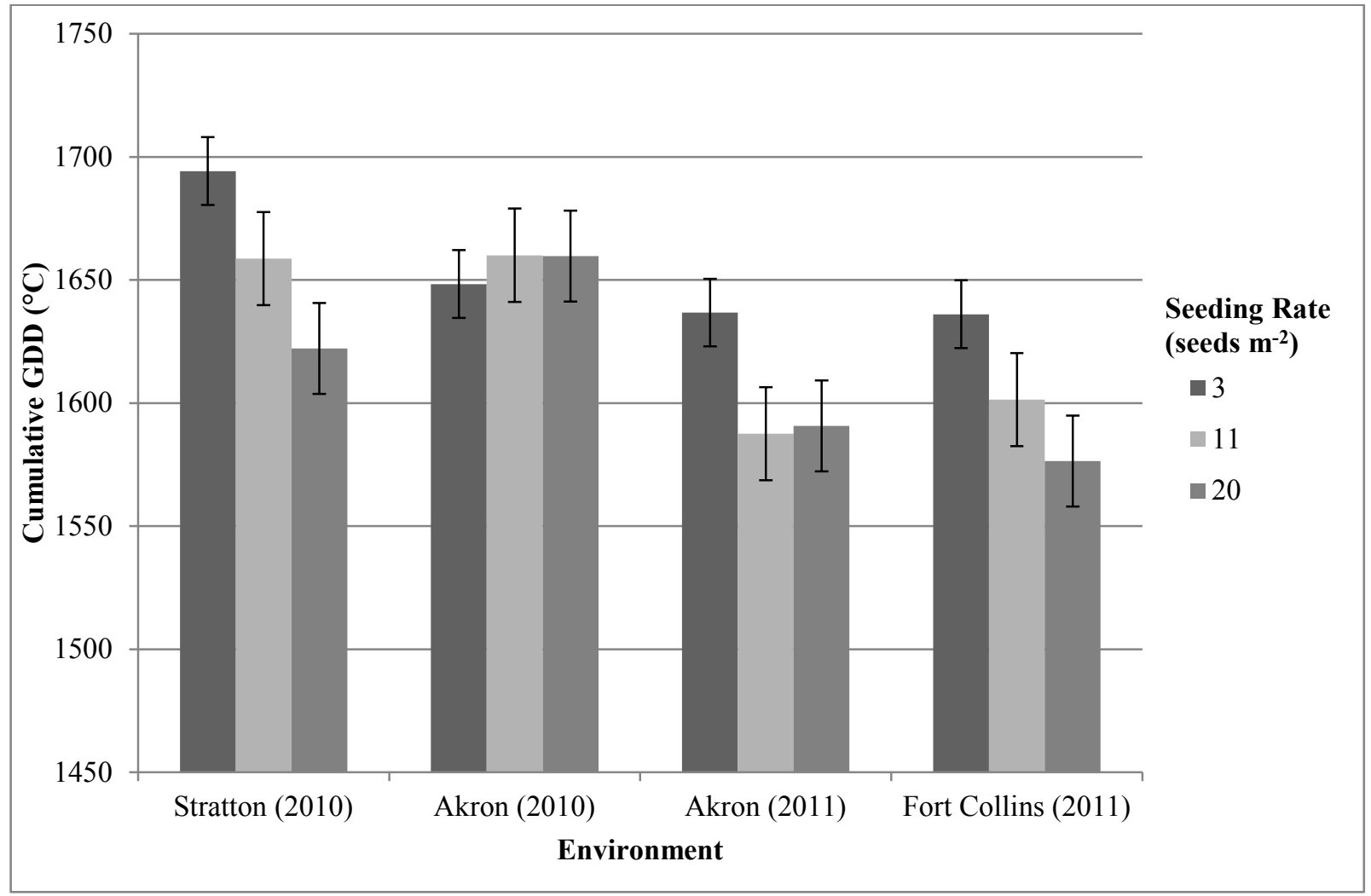

Figure 2. Cumulative growing degree-days from planting to physiological maturity for three seeding rates within environments in the north/south row orientation (experiment 1). All treatments within a location are pooled within an environment. 


\section{REFERENCES}

Baumhardt, R. L., J. A. Tolk, and S. R. Winter. "Seeding Practices and Cultivar Maturity Effects on Simulated Dryland Grain Sorghum Yield." Agronomy Journal 97.3 (2005): 935-42.

Bond, J. J., T. J. Army, and O. R. Lehman. "Row Spacing, Plant Populations and Moisture Supply as Factors in Dryland Grain Sorghum Production." Agronomy Journal 56.1 (1964): 3-6. American Society of Agronomy. Web. 3 Feb. 2012.

Eastin, Jerry D., Joe H. Hultquist, and C. Y. Sullivan. "Physiologic Maturity in Grain Sorghum." Crop Science 13.2 (1973): 175-78.

Ercoli, Laura, Marco Mariotti, Alessandro Masoni, and Iduna Arduini. "Growth Responses of Sorghum Plants to Chilling Temperature and Duration of Exposure." European Journal of Agronomy 21.1 (2004): 93-103. Science Direct. Web. 22 Jan. 2012.

Gerik, Thomas J., Brent Bean, and Richard L. Vanderlip. Sorghum Growth and Development. College Station, Texas: Texas Cooperative Extension, Texas A \& M University System, 2003.

Jones, Ordie R., and Grant L. Johnson. "Row Width and Plant Density Effects on Texas High Plains Sorghum." Journal of Production Agriculture 4.4 (1991): 613-19.

Jones, Ordie R. Evaluation of a Short Season-High Density Production Strategy for Dryland Sorghum. Rep. no. 95-5. Bushland: Conservation and Production Research Laboratory, 1995.

Kramer, Nicholas W., and William M. Ross. "Cultivation of Grain Sorghum in the United States." Sorghum Production and Utilization. Ed. Joseph S. Wall and William M. Ross. Westport, CT: Avi Pub., 1970. 167-99.

Lafarge, T. A., I. J. Broad, and G. L. Hammer. "Tillering in Grain Sorghum Over a Wide Range of Population Densities: Identification of a Common Hierarchy for Tiller Emergence, Leaf Area Development and Fertility." Annals of Botany 90.1 (2002): 87-98. Annals of Botany. Oxford Journals. Web. 2 Feb. 2012.

Larson, Kevin, and Dennis Thompson. "Dryland Grain Sorghum Seeding Rate and Seed Maturation, Brandon, 2010." Plainsman Research Center 2010 Research Reports (2011): 14-18.

Norcio, Norma V. The Effects of High Temperatures and Moisture Stress on Photosynthetic and Respiration Rates of Grain Sorghum. Diss. University of Nebraska-Lincoln, 1976. ETD Collection for University of Nebraska-Lincoln. University of Nebraska-Lincoln. Web. 15 Jan. 2012. <http://digitalcommons.unl.edu/dissertations/AAI7714681/>. 
Norwood, Charles A. "Water Use and Yield of Dryland Row Crops as Affected by Tillage." Agronomy Journal 91.1 (1999): 108-15.

Poehlman, John M. "Breeding Sorghum and Millet." Breeding Field Crops. 3rd ed. Westport, CT: AVI Publ., 1987. 508-55.

Quinby, J. Roy, and R. E. Karper. "The Inheritance of 3 Genes That Influence Time of Floral Initiation and Maturity Date in Milo." Journal of the American Society of Agronomy 37.11 (1945): 916-36.

Rooney, William L., and Selahattin Aydin. "Genetic Control of a Photoperiod-Sensitive Response in Sorghum Bicolor (L.) Moench." Crop Science 39.2 (1999): 397-400. Web. 4 Feb. 2012.

Roozeboom, Kraig, and Dale Fjell. "Selection of Grain Sorghum Hybrids." Grain Sorghum Production Handbook. Manhattan, Kansas: Kansas State University, 1998. 3-5.

Saeed, Mohammad, and C. A. Francis. "Yield Stability in Relation to Maturity in Grain Sorghum." Crop Science 23.4 (1983): 683-87.

SAS for Windows. Vers. 9.3. Cary, NC: SAS Institute, 2011. Computer software.

Schaffer, James A. The Effect of Planting Date and Environment on the Phenology and Modeling of Grain Sorghum, Sorghum Bicolor (L.) Moench. Diss. Kansas State University, 1980. Manhattan: Kansas State University, 1980.

Staggenborg, S. A., D. L. Fjell, D. L. Devlin, W. B. Gordon, and B. H. Marsh. "Grain Sorghum Response to Row Spacings and Seeding Rates in Kansas." Journal of Production Agriculture 12.3 (1999): 390-95

Staggenborg, S. A., K. C. Dhuyvetter, and W. B. Gordon. "Grain Sorghum and Corn Comparisons: Yield, Economic, and Environmental Responses." Agronomy Journal 100.6 (2008): 1600-604. Web. 10 Nov. 2011.

Staggenborg, Scott A., and Richard L. Vanderlip. "Sorghum Grain Yield Reductions Caused by Duration and Timing of Freezing Temperatures." Agronomy Journal 88.3 (1996): 473-77.

Steiner, J. L. "Dryland Grain Sorghum Water Use, Light Interception, and Growth Responses to Planting Geometry." Agronomy Journal 78.4 (1986): 720-26.

United States Department of Agriculture. National Agricultural Statistics Service. U.S. and All States Data-Crops. National Agricultural Statistics Service. Accessed on 28 Jan. 2012. 
Vigil, Merle F., W. B. Henry, F. J. Calderon, D. Poss, D. C. Nielsen, J. G. Benjamin, and Bob Klein. "A Use of Skip-Row Planting as a Strategy for Drought Mitigation in the West Central Great Plains." Proceedings of the Great Plains Soil Fertility Conference. Denver, CO. Vol. 12. 2008. 101-06.

Western Regional Climate Center." Western Regional Climate Center. National Climatic Data Center, 2012. Web. 15 Feb. 2012. <http://www.wrcc.dri.edu/>.

Witt, Merle D., R. L. Vanderlip, and L. D. Bark. "Effect of Row Width and Orientation on Light Intercepted by Grain Sorghum." Transactions of the Kansas Academy of Science 75.1 (1972): 29-40. JSTOR. Web. 23 Jan. 2012. 


\section{THESIS CONCLUSIONS}

The overall results from the grain sorghum maturity and yield studies show the importance of agronomic and environmental factors in grain sorghum production in Colorado. The purposes of the grain sorghum maturity and yield studies were not only to increase our knowledge about grain sorghum production in Colorado, but also to disseminate the research findings to dryland grain producers in the region. Both of those goals were met over the course of two years of field trials and multiple meetings and presentations with Colorado sorghum producers. The maturity study provided important information about grain sorghum physiology and production that not only applies to production in northeast Colorado, but to situations (such as re-plants or late-plantings) in other areas where early maturity may be critical.

Two experiments in the study failed, one due to herbicide damage and another from drought stress. The east/west row oriented experiment at Stratton in 2010 failed due to spray drift damage from a hooded sprayer. The second failed experiment occurred at Greeley in 2011 due to extreme drought stress on the dryland experiment 1 (north/south row orientation treatments). Site selection is important to consider when producing sorghum as controlling weeds can be hard since sorghum is not currently resistant to grass herbicides.

If we were able to do the study again, a few changes could be made to increase the value of information from the studies. Additional hybrid treatments from the early, medium-early, and medium maturity classes could be added to allow us to determine if the agronomic treatments affect all hybrids in the same manner regardless of maturity class, or if there are differences among classes or hybrids within classes. Two additional seeding rate treatments (at 7 and 15

seeds $\mathrm{m}^{-2}$ ) would be beneficial to allow us to create a seeding rate response curve based on 
cumulative GDD to maturity. Based on the results from our study, the row orientation treatments would not warrant further investigation in maturity trials as no trends were found on how orientation affects maturity. Since growing environments could be modeled to determine the adaptability of grain sorghum to a certain climate, it would not be beneficial to increase the number of trial locations. Future research in could be done to create a map of eastern Colorado with hypothetical probabilities of grain sorghum hybrids reaching physiological maturity based on one or more planting dates.

Even though a few problems occurred and changes could have been made to improve the studies, the overall goals were reached. Pertinent, quality data were collected from the trials. I not only learned about grain sorghum and its production from literature and talking to producers, but I was also able to learn from personal experience. I experienced how challenging (and rewarding) it can be to conduct, analyze, and report on field trials. I hope that the results of the thesis will inspire further research in grain sorghum production in Colorado so grain producers have access to more advanced technology for sorghum production in our area. 
APPENDICES 


\section{APPENDIX I}

TEST WEIGHT ANALYSIS RESULTS, ADDITIONAL TEST WEIGHT DATA, AND 2011 GREELEY WATER TREATMENT YIELD RESULTS

Table A1. ANOVA grain test weight results of three seeding rate, three hybrid, and two row spacing treatments in the north/south row orientation in 2011 at Akron and Fort Collins.

\begin{tabular}{lcc}
\hline Effect & df & P > F \\
\hline Environment (ENV) & 1 & 0.007 \\
Row Spacing (RS) & 1 & 0.006 \\
Hybrid (H) & 2 & $<0.001$ \\
Seeding rate (PR) & 2 & 0.313 \\
ENV X RS & 1 & 0.821 \\
ENV X H & 2 & 0.001 \\
ENV X PR & 2 & 0.853 \\
RS X H & 2 & 0.894 \\
RS X PR & 2 & 0.042 \\
H X PR & 4 & 0.086 \\
ENV X RS X H & 2 & 0.008 \\
ENV X RS X PR & 2 & 0.049 \\
ENV X H X PR & 4 & 0.304 \\
RS X H X PR & 4 & 0.037 \\
ENV X RS X H X PR & 3 & 0.186 \\
\hline
\end{tabular}




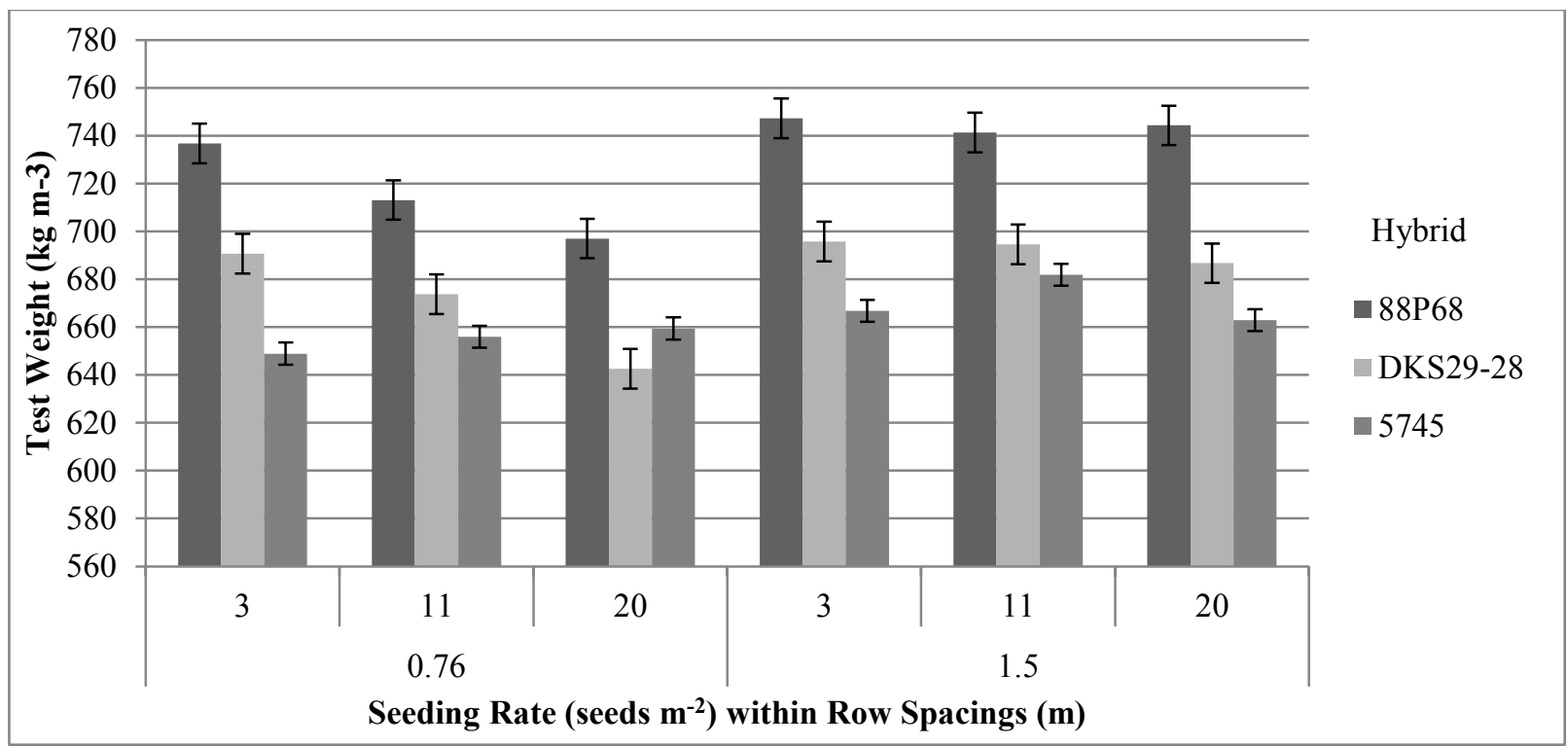

Figure A.1. Grain test weight results of three seeding rate, three hybrid, and two row spacing treatments in the north/south row orientation in 2011 averaged across Akron and Fort Collins.

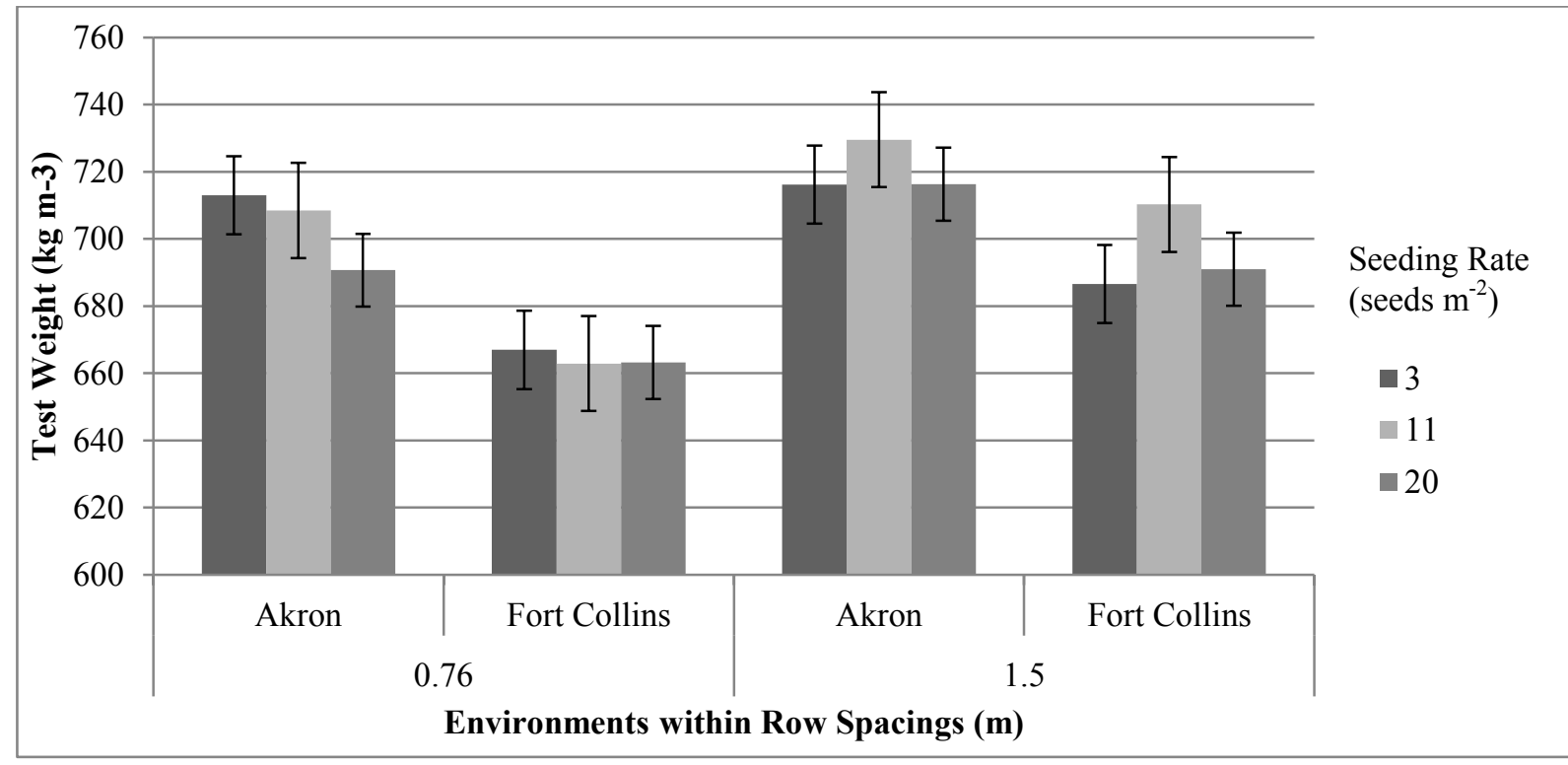

Figure A.2. Grain test weight results of three seeding rate and two row spacing treatments in the north/south row orientation in 2011 at Akron and Fort Collins averaged across hybrids. 


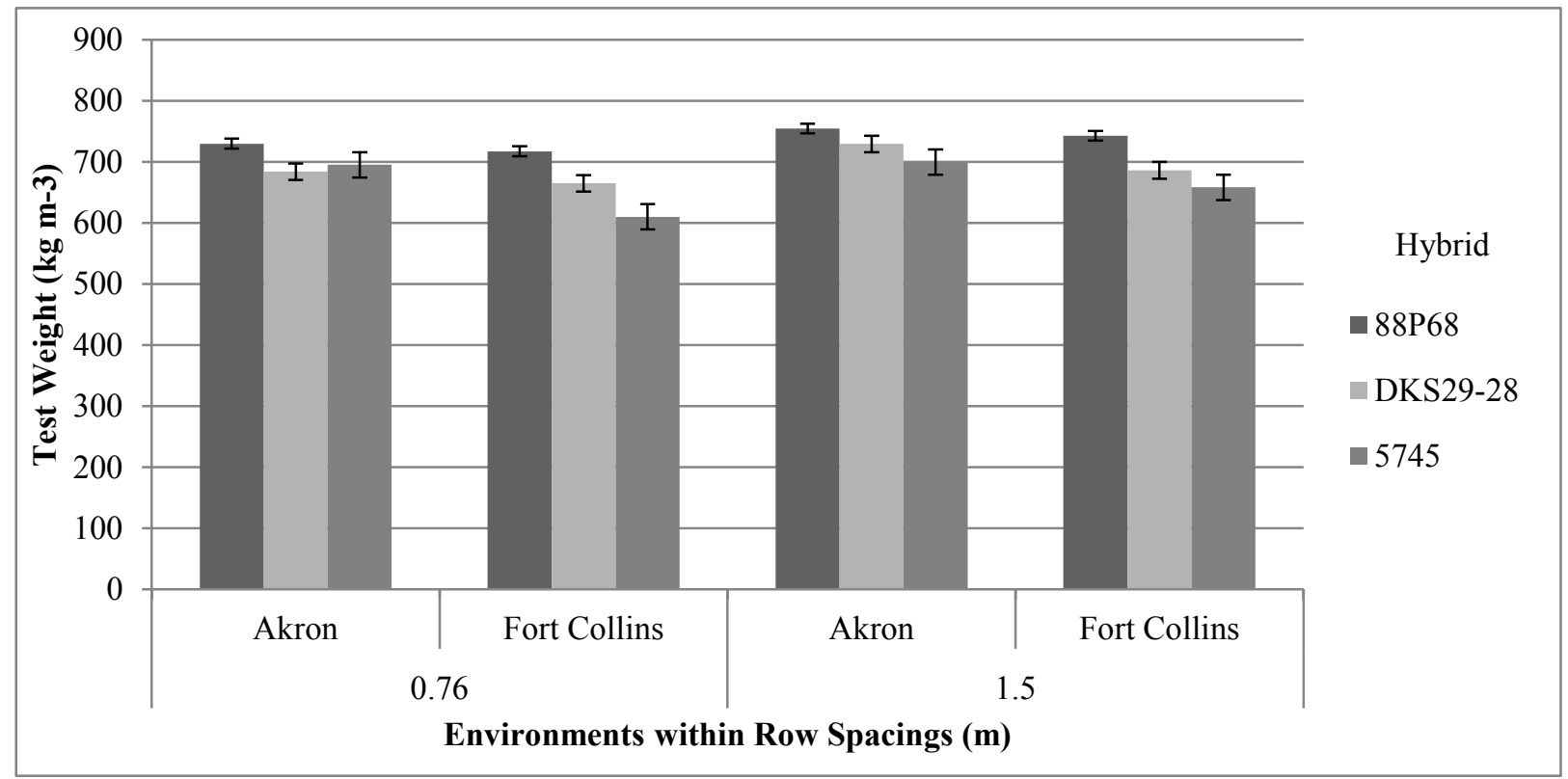

Figure A.3. Grain test weight results of three hybrid and two row spacing treatments in the north/south row orientation in 2011 at Akron and Fort Collins averaged across three seeding rates.

Table A2. Grain test weights in the east/west row orientation for five hybrids and two row spacings across two environments at a seeding rate of 11 seeds $\mathrm{m}^{-2}$.

\begin{tabular}{llccc}
\hline & & \multicolumn{2}{c}{ Row Spacing, $\mathrm{m}$} & \\
\cline { 3 - 4 } Environment & & \multicolumn{3}{c}{$\begin{array}{c}\text { Ove rall } \\
\text { Ave rage }\end{array}$} \\
\hline \multirow{3}{*}{ Stratton, 2010 } & Hybrid & 0.76 & $\mathrm{~kg} \mathrm{~m}^{-3}$ & \\
\cline { 3 - 4 } & & 651 & 681 & $\mathbf{6 6 0}$ \\
& 5745 & 703 & 704 & $\mathbf{7 0 4}$ \\
& $88 \mathrm{P} 68$ & 650 & 681 & $\mathbf{6 5 6}$ \\
& CGSH-8 & 678 & 691 & $\mathbf{6 8 1}$ \\
& DKS29-28 & 606 & 670 & $\mathbf{6 3 3}$ \\
\hline Akron, 2011 & & 696 & 690 & $\mathbf{6 9 3}$ \\
& 5745 & 688 & 708 & $\mathbf{6 9 8}$ \\
& $88 \mathrm{P} 68$ & 708 & 710 & $\mathbf{7 0 9}$ \\
& CGSH-9 & 669 & 589 & $\mathbf{6 1 6}$ \\
& DKS29-28 & 703 & 704 & $\mathbf{7 0 3}$ \\
\hline Ove rall Ave rage & & $\mathbf{6 7 3}$ & $\mathbf{6 8 8}$ & $\mathbf{6 7 9}$
\end{tabular}


Table A3. Grain test weights in the north/s outh row orientation for five hybrids, three seeding rates, and three row spacings across five environments.

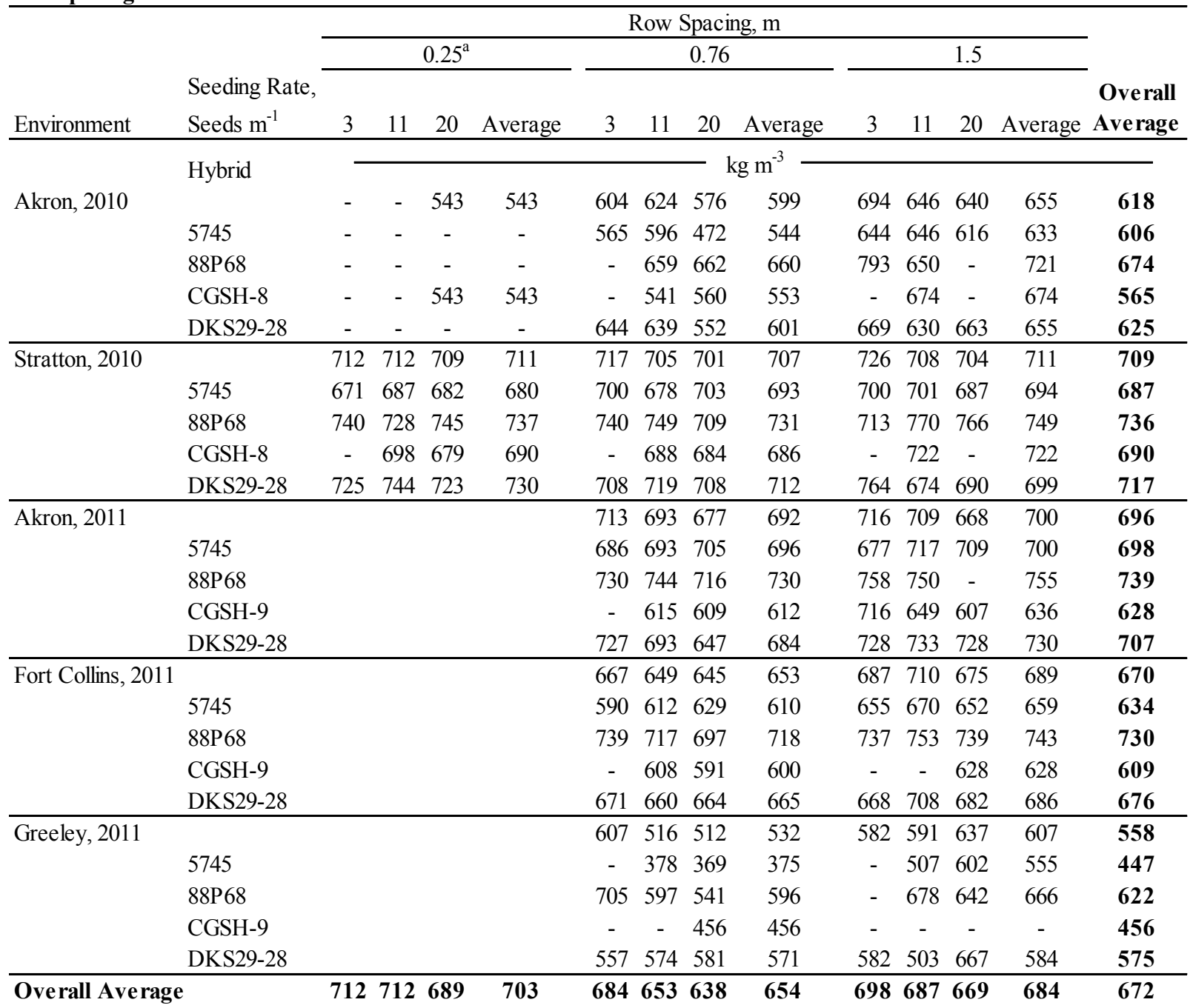

${ }^{\mathrm{a}}$ The $0.25 \mathrm{~m}$ row spacing treatment was not repeated in 2011 due to equipment and personnel constraints.

$\uparrow$ Dashes indicate missing data due to low grain harvest plot weights. 


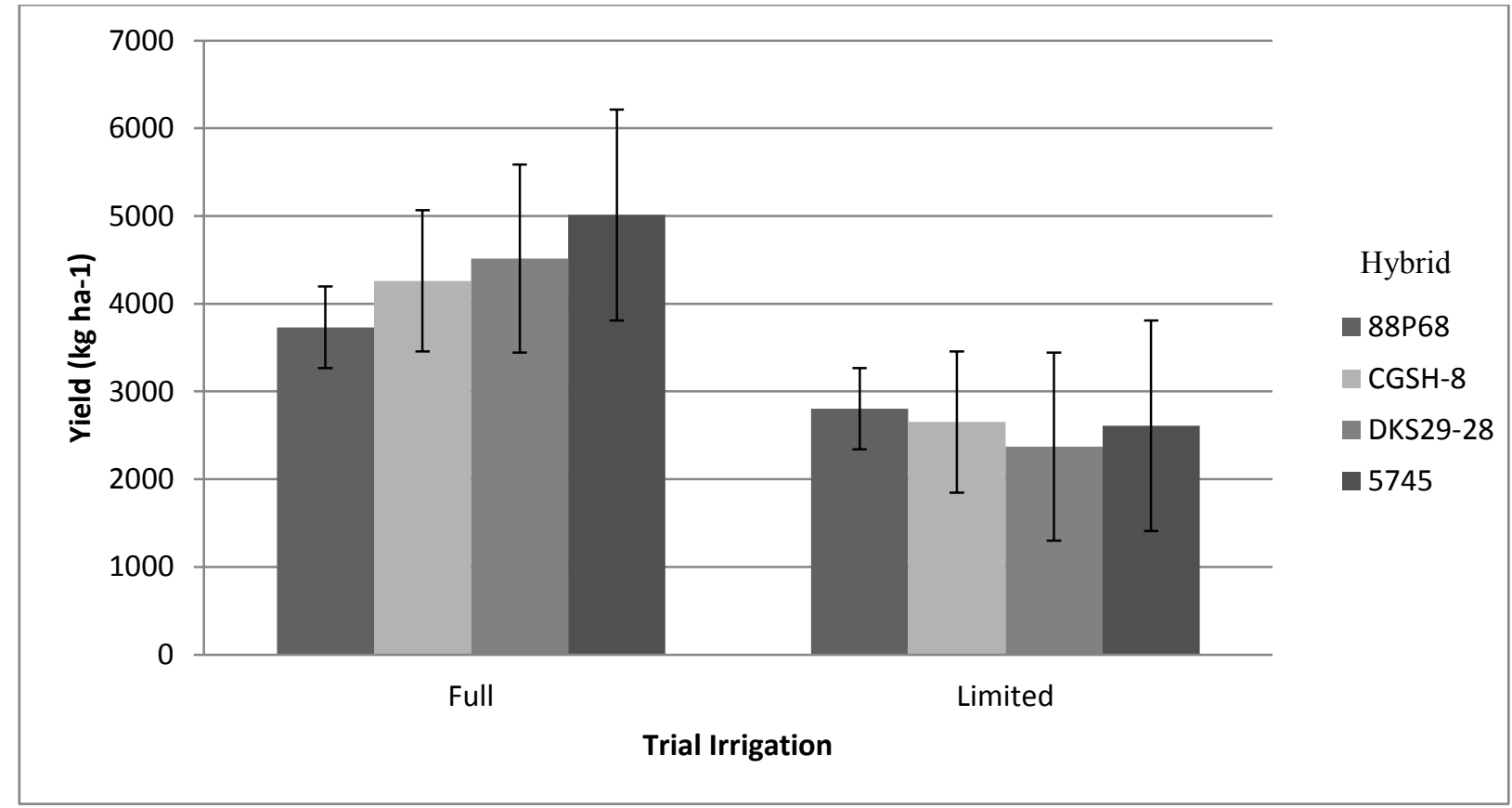

Figure A.4. Greeley 2011 yield results for four hybrids within two irrigation treatments planted at 11 seeds $\mathrm{m}^{-1}$ for the limited irrigation treatment and 20 seeds $\mathrm{m}^{-1}$ for the full irrigation treatment. 


\section{APPENDIX II}

ADDITIONAL YIELD, POPULATION, FLOWERING, MATURITY, AND LODGING DATA

FROM AKRON, FORT COLLINS, STRATTON, AND GREELEY IN 2010 AND 2011

Table A4. Grain yield in the north/s outh row orientation for five hybrids, three seeding rates, and three row spacings across five environments.

\begin{tabular}{|c|c|c|c|c|c|c|c|c|c|c|c|c|c|c|}
\hline \multirow[b]{3}{*}{ Environment } & \multirow{3}{*}{$\begin{array}{l}\text { Seeding Rate, } \\
\text { Seeds } \mathrm{m}^{-1}\end{array}$} & \multicolumn{12}{|c|}{ Row Spacing, $\mathrm{m}$} & \multirow{3}{*}{$\begin{array}{c}\text { Overall } \\
\text { Average }\end{array}$} \\
\hline & & \multicolumn{4}{|c|}{$0.25^{\mathrm{a}}$} & \multicolumn{4}{|c|}{0.76} & \multicolumn{4}{|c|}{1.5} & \\
\hline & & 3 & 11 & 20 & Average & 3 & 11 & 20 & Average & 3 & 11 & 20 & Average & \\
\hline & Hybrid & 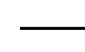 & 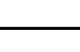 & - & 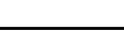 & 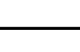 & 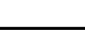 & - $\mathrm{kg}$ & $h^{-1}$ & & & & & \\
\hline \multirow[t]{5}{*}{ Akron, 2010} & & 422 & 795 & 1053 & 766 & 1115 & 1447 & 1438 & 1331 & 1720 & 2210 & 1901 & 1948 & 1370 \\
\hline & 5745 & 378 & 610 & 915 & 634 & 1135 & 964 & 819 & 972 & 1909 & 2771 & 2167 & 2282 & 1357 \\
\hline & 88Р68 & 371 & 899 & 715 & 657 & 1003 & 1784 & 1691 & 1493 & 1776 & 2146 & 1845 & 1922 & 1377 \\
\hline & CGSH-8 & 431 & 923 & 1282 & 919 & 1035 & 1428 & 1856 & 1440 & 1060 & 1901 & 1448 & 1507 & 1289 \\
\hline & DKS29-28 & 526 & 702 & 1183 & 829 & 1289 & 1607 & 1388 & 1428 & 1971 & 2021 & 2143 & 2045 & 1451 \\
\hline \multirow[t]{5}{*}{ Stratton, 2010} & & 2498 & 3780 & 4427 & 3550 & 2455 & 3014 & 2982 & 2824 & 1617 & 1949 & 2114 & 1893 & 2750 \\
\hline & 5745 & 2642 & 4112 & 5722 & 4159 & 3272 & 2749 & 3055 & 3026 & 1678 & 1755 & 2098 & 1844 & 3009 \\
\hline & 88Р68 & 2851 & 3860 & 3865 & 3494 & 2326 & 3268 & 2594 & 2729 & 1364 & 2180 & 2301 & 1948 & 2702 \\
\hline & CGSH-8 & 1443 & 3181 & 3305 & 2643 & 1127 & 2765 & 2932 & 2379 & 1675 & 1796 & 1296 & 1589 & 2199 \\
\hline & DKS29-28 & 3054 & 3969 & 4675 & 3900 & 2761 & 3273 & 3346 & 3127 & 1751 & 2065 & 2759 & 2192 & 3073 \\
\hline \multirow[t]{5}{*}{ Akron, 2011} & & & & & & 2309 & 3043 & 2850 & 2743 & 2756 & 2863 & 2911 & 2843 & 2794 \\
\hline & 5745 & & & & & 2485 & 3648 & 3294 & 3142 & 3702 & 3389 & 3371 & 3487 & 3315 \\
\hline & 88Р 68 & & & & & 2878 & 2376 & 2372 & 2542 & 3133 & 2650 & 2186 & 2656 & 2599 \\
\hline & CGSH-9 & & & & & 1072 & 2616 & 2465 & 2140 & 1471 & 2267 & 2825 & 2188 & 2165 \\
\hline & DKS29-28 & & & & & 2492 & 3531 & 3269 & 3097 & 2720 & 3145 & 3263 & 3042 & 3070 \\
\hline \multirow{5}{*}{ Fort Collins, 2011} & & & & & & 3618 & 4894 & 5408 & 4733 & 3495 & 5036 & 4125 & 4227 & 4495 \\
\hline & 5745 & & & & & 3814 & 5867 & 6666 & 5449 & 3224 & 4389 & 4384 & 3999 & 4724 \\
\hline & 88Р68 & & & & & 3159 & 5477 & 5412 & 4683 & 3644 & 5266 & 4756 & 4555 & 4619 \\
\hline & CGSH-9 & & & & & - & 2254 & 2888 & 2571 & - & - & 2135 & 2135 & 2426 \\
\hline & DKS29-28 & & & & & 3880 & 5975 & 6663 & 5506 & 3656 & 5452 & 5225 & 4880 & $\mathbf{5 2 0 7}$ \\
\hline \multirow[t]{5}{*}{ Greeley, 2011} & & & & & & 751 & 981 & 1169 & 967 & 703 & 1140 & 1191 & 1015 & 991 \\
\hline & 5745 & & & & & 459 & 773 & 845 & 692 & 582 & 977 & 984 & 848 & 770 \\
\hline & 88P68 & & & & & 796 & 1281 & 1321 & 1133 & 579 & 1596 & 1535 & 1297 & 1211 \\
\hline & CGSH-9 & & & & & 500 & 508 & 834 & 614 & 254 & 500 & 729 & 494 & 554 \\
\hline & DKS29-28 & & & & & 1249 & 1361 & 1675 & 1428 & 1368 & 1605 & 1513 & 1485 & 1456 \\
\hline Overall Average & & 1567 & 2336 & 2798 & 2236 & 1956 & 2691 & 2769 & 2484 & 1983 & 2532 & 2448 & 2327 & 2379 \\
\hline
\end{tabular}


Table A5. Grain yields in the e ast/we st row orientation for five hybrids and two row spacings across two environments at a seeding rate of 11 seeds $\mathrm{m}^{-2}$.

\begin{tabular}{llccc}
\hline & & \multicolumn{2}{c}{ Row Spacing, $\mathrm{m}$} & \\
\cline { 3 - 4 } Environment & & 0.76 & 1.5 & $\begin{array}{c}\text { Overall } \\
\text { Average }\end{array}$ \\
\cline { 3 - 4 } Stratton, 2010 & Hybrid & & $\mathrm{kg} \mathrm{ha}^{-1}$ & \\
\cline { 3 - 4 } & & 1724 & 1342 & $\mathbf{1 5 3 3}$ \\
& 5745 & 1572 & 1192 & $\mathbf{1 3 8 2}$ \\
& $88 \mathrm{P} 68$ & 1986 & 874 & $\mathbf{1 4 3 0}$ \\
& CGSH-8 & 1860 & 1442 & $\mathbf{1 6 5 1}$ \\
& DKS29-28 & 1478 & 1861 & $\mathbf{1 6 7 0}$ \\
\hline Akron, 2011 & & 2699 & 2606 & $\mathbf{2 6 5 6}$ \\
& 5745 & 3291 & 3051 & $\mathbf{3 1 8 8}$ \\
& $88 \mathrm{P} 68$ & 2732 & 2481 & $\mathbf{2 6 2 4}$ \\
& CGSH-9 & 1582 & 1683 & $\mathbf{1 6 3 3}$ \\
& DKS29-28 & 3192 & 3291 & $\mathbf{3 2 4 1}$ \\
\hline Overall Ave rage & $\mathbf{2 2 1 2}$ & $\mathbf{1 9 3 2}$ & $\mathbf{2 0 7 6}$
\end{tabular}


Table A6. Plant populations in the north/south row orientation for five hybrids, three seeding rates, and three row spacings across five environments.

\begin{tabular}{|c|c|c|c|c|c|c|c|c|c|c|c|c|c|c|}
\hline \multirow[b]{3}{*}{ Environment } & \multirow{3}{*}{$\begin{array}{l}\text { Seeding Rate, } \\
\text { Seeds } \mathrm{m}^{-1}\end{array}$} & \multicolumn{12}{|c|}{ Row Spacing, $\mathrm{m}$} & \multirow{3}{*}{$\begin{array}{r}\text { Overall } \\
\text { Average }\end{array}$} \\
\hline & & \multicolumn{4}{|c|}{$0.25^{\mathrm{a}}$} & \multicolumn{4}{|c|}{0.76} & \multicolumn{4}{|c|}{1.5} & \\
\hline & & 3 & 11 & 20 & Average & 3 & 11 & 20 & Average & 3 & 11 & 20 & Average & \\
\hline & Hybrid & & & & & & 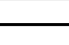 & plant & ts $\mathrm{m}^{-1}$ & & & & & \\
\hline \multirow[t]{5}{*}{ Akron, 2010} & & 2.6 & 10.3 & 18.1 & 10.3 & 2.8 & 9.3 & 15.0 & 9.0 & 2.2 & 8.7 & 11.1 & 7.5 & 8.9 \\
\hline & 5745 & 2.6 & 11.6 & 20.1 & 11.5 & 3.2 & 9.3 & 13.7 & 8.7 & 2.5 & 9.0 & 11.1 & 7.5 & 9.2 \\
\hline & $88 \mathrm{P} 68$ & 2.5 & 10.3 & 17.5 & 10.1 & 2.3 & 10.5 & 15.2 & 9.3 & 1.9 & 8.6 & 11.0 & 7.2 & 8.9 \\
\hline & CGSH-8 & 2.3 & 8.1 & 14.4 & 8.3 & 3.2 & 7.7 & 15.1 & 8.6 & 1.9 & 8.1 & 10.9 & 7.4 & 8.1 \\
\hline & DKS29-28 & 3.0 & 11.3 & 20.2 & 11.5 & 2.5 & 9.6 & 15.9 & 9.4 & 2.3 & 9.2 & 11.5 & 7.7 & 9.5 \\
\hline \multirow[t]{5}{*}{ Stratton, 2010} & & 2.5 & 8.0 & 10.8 & 7.1 & 2.6 & 7.8 & 11.8 & 7.4 & 2.5 & 5.4 & 6.6 & 4.9 & 6.6 \\
\hline & 5745 & 3.1 & 9.0 & 14.5 & 8.9 & 2.8 & 8.6 & 12.4 & 7.9 & 2.7 & 5.2 & 6.4 & 4.9 & 7.4 \\
\hline & $88 \mathrm{P} 68$ & 2.0 & 8.0 & 9.6 & 6.5 & 3.3 & 6.6 & 11.8 & 7.3 & 2.1 & 5.5 & 6.8 & 4.8 & 6.3 \\
\hline & CGSH-8 & 2.5 & 7.0 & 7.8 & 5.8 & 1.6 & 6.8 & 10.3 & 6.2 & 2.0 & 4.9 & 5.5 & 4.1 & 5.5 \\
\hline & DKS29-28 & 2.5 & 8.2 & 11.4 & 7.4 & 2.8 & 9.0 & 12.8 & 8.2 & 3.2 & 6.1 & 7.9 & 5.8 & 7.2 \\
\hline \multirow[t]{5}{*}{ Akron, 2011} & & & & & & 0.9 & 3.2 & 4.6 & 2.9 & 1.9 & 6.5 & 9.0 & 5.8 & 4.4 \\
\hline & 5745 & & & & & 1.2 & 4.1 & 6.6 & 4.0 & 2.3 & 8.9 & 12.5 & 7.9 & 5.9 \\
\hline & $88 \mathrm{P} 68$ & & & & & 1.1 & 3.5 & 5.3 & 3.3 & 2.2 & 7.9 & 9.8 & 6.6 & 5.0 \\
\hline & CGSH-9 & & & & & 0.2 & 0.8 & 0.8 & 0.6 & 0.6 & 1.3 & 2.0 & 1.3 & 0.9 \\
\hline & DKS29-28 & & & & & 1.0 & 4.3 & 5.8 & 3.7 & 2.5 & 8.1 & 11.9 & 7.5 & 5.6 \\
\hline \multirow[t]{5}{*}{ Fort Collins, 2011} & & & & & & 1.7 & 5.9 & 10.1 & 5.9 & 1.9 & 5.7 & 7.8 & 5.1 & 5.5 \\
\hline & 5745 & & & & & 2.4 & 8.3 & 13.5 & 8.1 & 2.7 & 7.9 & 7.7 & 6.1 & 7.1 \\
\hline & $88 \mathrm{P} 68$ & & & & & 1.8 & 6.8 & 11.5 & 6.7 & 2.1 & 6.7 & 8.9 & 5.9 & 6.3 \\
\hline & CGSH-9 & & & & & 0.5 & 1.7 & 3.2 & 1.8 & 0.4 & 1.5 & 2.2 & 1.4 & 1.6 \\
\hline & DKS29-28 & & & & & 2.1 & 6.6 & 12.3 & 7.0 & 2.3 & 6.5 & 12.3 & 7.0 & 7.0 \\
\hline \multirow[t]{5}{*}{ Greeley, 2011} & & & & & & 2.1 & 7.2 & 13.3 & 7.5 & 2.1 & 7.3 & 10.9 & 6.8 & 7.1 \\
\hline & 5745 & & & & & 2.4 & 8.5 & 17.3 & 9.4 & 3.0 & 8.2 & 13.2 & 8.2 & 8.8 \\
\hline & $88 \mathrm{P} 68$ & & & & & 2.5 & 7.9 & 14.7 & 8.4 & 2.5 & 8.5 & 12.8 & 7.9 & 8.2 \\
\hline & CGSH-9 & & & & & 0.8 & 2.5 & 5.9 & 3.1 & 0.5 & 2.4 & 5.0 & 2.6 & 2.8 \\
\hline & DKS29-28 & & & & & 2.8 & 9.8 & 15.1 & 9.2 & 2.3 & 10.0 & 12.8 & 8.4 & 8.8 \\
\hline Overall Average & & 2.6 & 9.2 & 14.4 & 8.7 & 2.0 & 6.7 & 11.0 & 6.5 & 2.1 & 6.8 & 9.2 & 6.1 & 6.7 \\
\hline
\end{tabular}

${ }^{\mathrm{a}}$ The $0.25 \mathrm{~m}$ row spacing treatment was not repeated in 2011 due to equipment and personnel constraints. 
Table A7. Plant populations in the east/west row orientation for five hybrids and two row spacings across three environments at a seeding rate of 11 seeds $\mathrm{m}^{-2}$.

\begin{tabular}{|c|c|c|c|c|}
\hline \multirow[b]{2}{*}{ Environment } & & \multicolumn{2}{|c|}{ Row Spacing, $m$} & \multirow{2}{*}{$\begin{array}{r}\text { Overall } \\
\text { Average }\end{array}$} \\
\hline & & 0.76 & 1.5 & \\
\hline \multirow[t]{5}{*}{ Akron, 2010} & Hybrid & 9.3 & $\begin{array}{c}\text { plants } \mathrm{m}^{-} \\
8.5\end{array}$ & 8.9 \\
\hline & 5745 & 10.0 & 9.5 & 9.7 \\
\hline & 88Р 68 & 8.1 & 8.0 & 8.1 \\
\hline & CGSH-8 & 8.1 & 7.1 & 7.6 \\
\hline & DKS29-28 & 10.8 & 9.5 & 10.2 \\
\hline \multirow[t]{5}{*}{ Stratton, 2010} & & 5.9 & 5.2 & 5.6 \\
\hline & 5745 & 6.1 & 5.8 & 6.0 \\
\hline & 88Р 68 & 5.3 & 4.9 & 5.1 \\
\hline & CGSH-8 & 4.5 & 3.6 & 4.1 \\
\hline & DKS29-28 & 7.6 & 6.5 & 7.0 \\
\hline \multirow[t]{5}{*}{ Akron, 2011} & & 3.6 & 6.9 & 5.3 \\
\hline & 5745 & 4.9 & 8.8 & 6.9 \\
\hline & 88Р68 & 4.1 & 8.4 & 6.2 \\
\hline & CGSH-9 & 0.7 & 1.3 & 1.0 \\
\hline & DKS29-28 & 4.7 & 9.1 & 6.9 \\
\hline Overall Aver & & 6.3 & 6.9 & 6.6 \\
\hline
\end{tabular}


Table A8. Cumulative growing degree-days to half-bloom in the north/south row orientation for five hybrids, three seeding rates, and three row spacings across four environments.

\begin{tabular}{|c|c|c|c|c|c|c|c|c|c|c|c|c|c|c|}
\hline \multirow[b]{3}{*}{ Environment $^{\mathrm{b}}$} & \multirow{3}{*}{$\begin{array}{l}\text { Seeding Rate, } \\
\text { Seeds } \mathrm{m}^{-1}\end{array}$} & \multicolumn{12}{|c|}{ Row Spacing, $m$} & \multirow{3}{*}{$\begin{array}{r}\text { Overall } \\
\text { Average }\end{array}$} \\
\hline & & \multicolumn{4}{|c|}{$0.25^{\mathrm{a}}$} & \multicolumn{4}{|c|}{0.76} & \multicolumn{4}{|c|}{1.5} & \\
\hline & & 3 & 11 & 20 & Average & 3 & 11 & 20 & Average & 3 & 11 & 20 & Average & \\
\hline & Hybrid & & & & & & gro & wing de & gree-days & & & & & \\
\hline \multirow[t]{5}{*}{ Stratton, 2010} & & 1,115 & 1,110 & 1,120 & 1,115 & 1,114 & 1,115 & 1,119 & 1,116 & 1,162 & 1,135 & 1,119 & 1,137 & 1,122 \\
\hline & 5745 & 1,164 & 1,159 & 1,238 & 1,187 & 1,140 & 1,195 & 1,173 & 1,169 & 1,307 & 1,176 & 1,235 & 1,245 & 1,199 \\
\hline & $88 \mathrm{P} 68$ & 1,107 & 1,098 & 1,089 & 1,098 & 1,118 & 1,097 & 1,125 & 1,113 & 1,091 & 1,113 & 1,080 & 1,095 & 1,102 \\
\hline & CGSH-8 & 1,085 & 1,085 & 1,062 & 1,077 & 1,097 & 1,071 & 1,071 & 1,078 & 1,104 & 1,081 & 1,066 & 1,083 & 1,080 \\
\hline & DKS29-28 & 1,102 & 1,098 & 1,089 & 1,096 & 1,091 & 1,096 & 1,107 & 1,099 & 1,117 & 1,179 & 1,093 & 1,131 & 1,108 \\
\hline \multirow[t]{5}{*}{ Akron, 2011} & & & & & & 1,199 & 1,202 & 1,180 & 1,195 & 1,190 & 1,159 & 1,160 & 1,170 & 1,182 \\
\hline & 5745 & & & & & 1,278 & 1,273 & 1,201 & 1,264 & 1,284 & 1,189 & 1,213 & 1,229 & 1,244 \\
\hline & $88 \mathrm{P} 68$ & & & & & 1,155 & 1,122 & 1,142 & 1,140 & 1,122 & 1,109 & 1,087 & 1,106 & 1,123 \\
\hline & CGSH-9 & & & & & 1,254 & 1,273 & 1,297 & 1,275 & 1,242 & 1,240 & 1,241 & 1,241 & 1,256 \\
\hline & DKS29-28 & & & & & 1,151 & 1,141 & 1,106 & 1,134 & 1,137 & 1,108 & 1,113 & 1,119 & 1,126 \\
\hline \multirow[t]{5}{*}{ Fort Collins, 2011} & & & & & & 1,076 & 1,063 & 1,056 & 1,065 & 1,078 & 1,058 & 1,049 & 1,062 & 1,063 \\
\hline & 5745 & & & & & 1,148 & 1,121 & 1,092 & 1,121 & 1,130 & 1,110 & 1,126 & 1,122 & 1,121 \\
\hline & $88 \mathrm{P} 68$ & & & & & 1,050 & 1,042 & 1,031 & 1,041 & 1,039 & 1,020 & 1,005 & 1,021 & 1,031 \\
\hline & CGSH-9 & & & & & 1,055 & 1,042 & 1,062 & 1,053 & 1,065 & 1,073 & 1,042 & 1,060 & 1,057 \\
\hline & DKS29-28 & & & & & 1,046 & 1,046 & 1,039 & 1,043 & 1,077 & 1,031 & 1,023 & 1,043 & 1,043 \\
\hline \multirow[t]{5}{*}{ Greeley, 2011} & & & & & & 1,076 & 1,058 & 1,074 & 1,070 & 1,085 & 1,063 & 1,059 & 1,069 & 1,070 \\
\hline & 5745 & & & & & 1,157 & 1,154 & 1,119 & 1,143 & 1,138 & 1,118 & 1,139 & 1,130 & 1,137 \\
\hline & 88Р 68 & & & & & 1,059 & 1,050 & 1,066 & 1,058 & 1,100 & 1,028 & 1,043 & 1,057 & 1,058 \\
\hline & CGSH-9 & & & & & 1,055 & 1,022 & 1,049 & 1,042 & 1,053 & 1,049 & 1,035 & 1,046 & 1,044 \\
\hline & DKS29-28 & & & & & 1,035 & 1,054 & 1,074 & 1,055 & 1,062 & 1,058 & 1,040 & 1,053 & 1,054 \\
\hline Overall Averag & & 1,115 & 1,110 & 1,120 & 1,115 & 1,111 & 1,111 & 1,102 & 1,108 & 1,127 & 1,103 & 1,096 & 1,109 & 1,109 \\
\hline
\end{tabular}

${ }^{a}$ The $0.25 \mathrm{~m}$ row spacing treatment was not repeated in 2011 due to equipment and personnel constraints.

${ }^{\mathrm{b}}$ The flowering growing degree-days data was not available for the Akron 2010 environment (environment therefore not listed in the table). 
Table A9. Cumulative growing degree-days to half-bloom in the east/west row orientation for five hybrids and two row spacings across three environments at a seeding rate of 11 seeds $\mathrm{m}^{-2}$.

\begin{tabular}{|c|c|c|c|c|}
\hline \multirow[b]{2}{*}{ Environment } & & \multicolumn{2}{|c|}{ Row Spacing, $\mathrm{m}$} & \multirow{2}{*}{$\begin{array}{r}\text { Overall } \\
\text { Average }\end{array}$} \\
\hline & & 0.76 & 1.5 & \\
\hline & Hybrid & \multicolumn{3}{|c|}{ growing degree-days } \\
\hline \multirow[t]{5}{*}{ Akron, 2010} & & 1,124 & 1,113 & 1,119 \\
\hline & 5745 & 1,236 & 1,218 & 1,227 \\
\hline & $88 \mathrm{P} 68$ & 1,096 & 1,114 & 1,105 \\
\hline & CGSH-8 & 1,054 & 1,034 & 1,044 \\
\hline & DKS29-28 & 1,110 & 1,088 & 1,099 \\
\hline \multirow[t]{5}{*}{ Stratton, 2010} & & 1,286 & 1,246 & 1,266 \\
\hline & 5745 & 1,332 & 1,365 & 1,349 \\
\hline & $88 \mathrm{P} 68$ & 1,211 & 1,252 & 1,232 \\
\hline & CGSH-8 & 1,297 & 1,175 & 1,236 \\
\hline & DKS29-28 & 1,303 & 1,191 & 1,247 \\
\hline \multirow[t]{5}{*}{ Akron, 2011} & & 1,185 & 1,157 & 1,170 \\
\hline & 5745 & 1,258 & 1,187 & 1,217 \\
\hline & $88 \mathrm{P} 68$ & 1,142 & 1,105 & 1,124 \\
\hline & CGSH-9 & 1,253 & 1,239 & 1,245 \\
\hline & DKS29-28 & 1,122 & 1,096 & 1,109 \\
\hline Overall Aver & & 1,199 & 1,172 & 1,185 \\
\hline
\end{tabular}


Table A10. Cumulative growing degree-days to maturity in the north/south row orientation for five hybrids, three seeding rates, and three row spacings across five environments.

\begin{tabular}{|c|c|c|c|c|c|c|c|c|c|c|c|c|c|c|}
\hline \multirow[b]{3}{*}{ Environment } & \multirow{3}{*}{$\begin{array}{l}\text { Seeding Rate, } \\
\text { Seeds } \mathrm{m}^{-1}\end{array}$} & \multicolumn{12}{|c|}{ Row Spacing, $\mathrm{m}$} & \multirow{3}{*}{$\begin{array}{r}\text { Overall } \\
\text { Average }\end{array}$} \\
\hline & & \multicolumn{4}{|c|}{$0.25^{\mathrm{a}}$} & \multicolumn{4}{|c|}{0.76} & \multicolumn{4}{|c|}{1.5} & \\
\hline & & 3 & 11 & 20 & Average & 3 & 11 & 20 & Average & 3 & 11 & 20 & Average & \\
\hline \multirow{6}{*}{ Akron, 2010} & Hybrid & & & & & & - gro & wing de & gree-days & & & & & 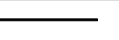 \\
\hline & & 1,631 & 1,648 & 1,667 & 1,648 & 1,628 & 1,640 & 1,642 & 1,636 & 1,643 & 1,637 & 1,639 & 1,640 & 1,641 \\
\hline & 5745 & 1,735 & 1,727 & 1,719 & 1,729 & 1,697 & 1,719 & 1,726 & 1,713 & 1,702 & 1,715 & 1,701 & 1,706 & 1,714 \\
\hline & $88 \mathrm{P} 68$ & 1,609 & 1,623 & 1,674 & 1,635 & 1,617 & 1,607 & 1,627 & 1,617 & 1,623 & 1,616 & 1,614 & 1,618 & 1,623 \\
\hline & CGSH-8 & 1,578 & 1,587 & 1,581 & 1,582 & 1,582 & 1,574 & 1,572 & 1,576 & 1,605 & 1,574 & 1,597 & 1,591 & 1,583 \\
\hline & DKS29-28 & 1,603 & 1,695 & 1,720 & 1,673 & 1,617 & 1,660 & 1,664 & 1,647 & 1,634 & 1,644 & 1,644 & 1,640 & 1,653 \\
\hline \multirow[t]{5}{*}{ Stratton, 2010} & & 1,615 & 1,595 & 1,585 & 1,598 & 1,664 & 1,640 & 1,612 & 1,638 & 1,688 & 1,633 & 1,598 & 1,634 & 1,621 \\
\hline & 5745 & 1,692 & 1,666 & 1,669 & 1,675 & 1,772 & 1,715 & 1,654 & 1,713 & 1,731 & 1,683 & 1,638 & 1,677 & 1,689 \\
\hline & 88Р 68 & 1,579 & 1,552 & 1,538 & 1,557 & 1,597 & 1,645 & 1,606 & 1,619 & 1,680 & 1,554 & 1,585 & 1,601 & 1,589 \\
\hline & CGSH-8 & 1,542 & 1,550 & 1,521 & 1,538 & 1,625 & 1,568 & 1,540 & 1,578 & 1,587 & 1,550 & 1,557 & 1,564 & 1,557 \\
\hline & DKS29-28 & 1,646 & 1,610 & 1,611 & 1,622 & 1,662 & 1,606 & 1,639 & 1,636 & 1,730 & 1,708 & 1,617 & 1,685 & 1,645 \\
\hline \multirow[t]{5}{*}{ Akron, 2011} & & & & & & 1,644 & 1,611 & 1,613 & 1,622 & 1,637 & 1,609 & 1,606 & 1,617 & 1,620 \\
\hline & 5745 & & & & & 1,688 & 1,638 & 1,635 & 1,653 & 1,703 & 1,638 & 1,623 & 1,655 & 1,654 \\
\hline & $88 \mathrm{P} 68$ & & & & & 1,626 & 1,575 & 1,596 & 1,599 & 1,587 & 1,542 & 1,567 & 1,565 & 1,582 \\
\hline & CGSH-9 & & & & & 1,627 & 1,669 & 1,674 & 1,658 & 1,672 & 1,687 & 1,673 & 1,677 & 1,669 \\
\hline & DKS29-28 & & & & & 1,632 & 1,562 & 1,562 & 1,585 & 1,585 & 1,570 & 1,562 & 1,572 & 1,579 \\
\hline \multirow[t]{5}{*}{ Fort Collins, 2011} & & & & & & 1,640 & 1,615 & 1,583 & 1,612 & 1,624 & 1,592 & 1,583 & 1,600 & 1,606 \\
\hline & 5745 & & & & & 1,677 & 1,665 & 1,614 & 1,652 & 1,679 & 1,629 & 1,637 & 1,648 & 1,650 \\
\hline & $88 \mathrm{P} 68$ & & & & & 1,640 & 1,601 & 1,567 & 1,603 & 1,600 & 1,558 & 1,538 & 1,565 & 1,584 \\
\hline & CGSH-9 & & & & & 1,633 & 1,614 & 1,596 & 1,611 & 1,605 & 1,607 & 1,613 & 1,608 & 1,609 \\
\hline & DKS29-28 & & & & & 1,608 & 1,580 & 1,557 & 1,582 & 1,613 & 1,574 & 1,546 & 1,578 & 1,580 \\
\hline \multirow[t]{5}{*}{ Greeley, 2011} & & & & & & 1,552 & 1,530 & 1,532 & 1,538 & 1,548 & 1,534 & 1,526 & 1,536 & 1,537 \\
\hline & 5745 & & & & & 1,579 & 1,532 & 1,542 & 1,553 & 1,565 & 1,536 & 1,532 & 1,544 & 1,548 \\
\hline & 88Р68 & & & & & 1,553 & 1,520 & 1,532 & 1,536 & 1,540 & 1,516 & 1,504 & 1,522 & 1,530 \\
\hline & CGSH-9 & & & & & 1,554 & 1,553 & 1,547 & 1,551 & 1,541 & 1,539 & 1,536 & 1,539 & 1,544 \\
\hline & DKS29-28 & & & & & 1,530 & 1,520 & 1,513 & 1,521 & 1,549 & 1,544 & 1,524 & 1,538 & 1,529 \\
\hline Overall Average & & 1,623 & 1,620 & 1,623 & 1,622 & 1,626 & 1,611 & 1,597 & 1,611 & 1,624 & 1,601 & 1,594 & 1,606 & 1,611 \\
\hline
\end{tabular}

${ }^{\mathrm{a}}$ The $0.25 \mathrm{~m}$ row spacing treatment was not repeated in 2011 due to equipment and personnel constraints. 
Table A11. Cumulative growing degree-days to maturity in the east/west row orientation for five hybrids and two row spacings across three environments at a seeding rate of 11 seeds $\mathrm{m}^{-2}$.

\begin{tabular}{|c|c|c|c|c|}
\hline \multirow[b]{2}{*}{ Environment } & & \multicolumn{2}{|c|}{ Row Spacing, $\mathrm{m}$} & \multirow{2}{*}{$\begin{array}{r}\text { Overall } \\
\text { Average }\end{array}$} \\
\hline & & 0.76 & 1.5 & \\
\hline & Hybrid & gro & hg degr & -days \\
\hline \multirow[t]{5}{*}{ Akron, 2010} & & 1,628 & 1,624 & 1,626 \\
\hline & 5745 & 1,677 & 1,688 & 1,682 \\
\hline & $88 \mathrm{P} 68$ & 1,622 & 1,610 & 1,616 \\
\hline & CGSH-8 & 1,565 & 1,570 & 1,567 \\
\hline & DKS29-28 & 1,647 & 1,628 & 1,637 \\
\hline \multirow[t]{5}{*}{ Stratton, 2010} & & 2,358 & 2,380 & 2,367 \\
\hline & 5745 & - & 2,439 & 2,439 \\
\hline & $88 \mathrm{P} 68$ & 2,358 & - & 2,358 \\
\hline & CGSH-8 & - & - & - \\
\hline & DKS29-28 & - & 2,321 & 2,321 \\
\hline \multirow[t]{5}{*}{ Akron, 2011} & & 1,609 & 1,613 & 1,611 \\
\hline & 5745 & 1,641 & 1,632 & 1,636 \\
\hline & $88 \mathrm{P} 68$ & 1,574 & 1,589 & 1,582 \\
\hline & CGSH-9 & 1,653 & 1,653 & 1,653 \\
\hline & DKS29-28 & 1,569 & 1,578 & 1,573 \\
\hline Overall Aver & & 1,682 & 1,663 & 1,673 \\
\hline
\end{tabular}

$\dagger$ Dashes indicate missing data due to severe herbicide damage in Stratton in 2010. 
Table A12. Plant lodging scores at harvest in two row orientations for five hybrids, three seeding rates, and three row spacings across two environments.

\begin{tabular}{|c|c|c|c|c|c|c|c|c|c|c|c|c|c|c|c|c|c|}
\hline \multirow[b]{3}{*}{ Environment } & \multirow{3}{*}{$\begin{array}{l}\text { Row Spacing, } \mathrm{m} \\
\text { Seeding Rate, } \\
\text { Seeds } \mathrm{m}^{-1}\end{array}$} & \multicolumn{13}{|c|}{ North/South Row Orientation } & \multicolumn{3}{|c|}{$\begin{array}{c}\text { East/West Row } \\
\text { Orientation }\end{array}$} \\
\hline & & \multicolumn{4}{|c|}{$0.25^{\mathrm{a}}$} & \multicolumn{4}{|c|}{0.76} & \multicolumn{4}{|c|}{1.5} & \multirow{2}{*}{$\begin{array}{c}\text { North/ } \\
\text { South } \\
\text { Average } \\
\end{array}$} & \multirow{2}{*}{$\begin{array}{c}0.76 \\
11 \\
\end{array}$} & \multirow{2}{*}{$\begin{array}{l}1.5 \\
11 \\
\end{array}$} & \multirow{2}{*}{$\begin{array}{r}\text { East/ } \\
\text { West } \\
\text { Average } \\
\end{array}$} \\
\hline & & 3 & 11 & 20 & Avg. & 3 & 11 & 20 & Avg. & 3 & 11 & 20 & Avg. & & & & \\
\hline & Hybrid & & & & 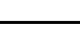 & . & . & 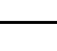 & - lod & ing ra & anking & $g(0-1$ & $10)^{\mathrm{b}}$ & & & & \\
\hline \multirow[t]{5}{*}{ Stratton, 2010} & & 1.0 & 2.1 & 2.5 & 1.9 & 0.9 & 1.3 & 1.5 & 1.2 & 0.8 & 0.6 & 1.9 & 1.1 & 1.4 & - & - & - \\
\hline & 5745 & 1.5 & 2.5 & 0.0 & 1.3 & 0.0 & 0.0 & 2.5 & 0.8 & 0.0 & 1.5 & 1.5 & 1.0 & 1.1 & - & - & - \\
\hline & $88 \mathrm{P} 68$ & 0.5 & 1.5 & 1.5 & 1.2 & 1.5 & 4.0 & 2.0 & 2.5 & 0.0 & 1.0 & 1.5 & 0.8 & 1.5 & - & - & - \\
\hline & CGSH-8 & 0.0 & 3.0 & 2.0 & 1.7 & 2.0 & 1.0 & 1.5 & 1.5 & 1.0 & 0.0 & 3.5 & 1.5 & 1.6 & - & - & - \\
\hline & DKS29-28 & 2.0 & 1.5 & 6.5 & 3.3 & 0.0 & 0.0 & 0.0 & 0.0 & 2.7 & 0.0 & 1.0 & 1.1 & 1.5 & - & - & - \\
\hline \multirow[t]{5}{*}{ Akron, 2011} & & & & & & 1.3 & 2.1 & 2.1 & 1.8 & 1.6 & 1.9 & 2.6 & 2.1 & 1.9 & 3.5 & 4.5 & 4.0 \\
\hline & 5745 & & & & & 1.0 & 1.0 & 1.0 & 1.0 & 1.0 & 1.0 & 1.0 & 1.0 & 1.0 & 2.0 & 3.3 & 2.6 \\
\hline & 88P68 & & & & & 2.0 & 5.3 & 5.0 & 4.1 & 3.5 & 4.3 & 6.8 & 4.8 & 4.5 & 7.5 & 8.3 & 7.9 \\
\hline & CGSH-9 & & & & & 1.0 & 1.0 & 1.0 & 1.0 & 1.0 & 1.0 & 1.0 & 1.0 & 1.0 & 2.0 & 1.5 & 1.8 \\
\hline & DKS29-28 & & & & & 1.3 & 1.0 & 1.3 & 1.2 & 1.0 & 1.5 & 1.8 & 1.4 & 1.3 & 2.5 & 5.0 & 3.8 \\
\hline Overall Ave & & 1.0 & 2.1 & 2.5 & 1.9 & 1.1 & 1.7 & 1.8 & 1.5 & 1.2 & 1.3 & 2.3 & 1.6 & 1.6 & 3.5 & 4.5 & 4.0 \\
\hline
\end{tabular}

${ }^{a}$ The $0.25 \mathrm{~m}$ row spacing treatment was not repeated in 2011 due to equipment and personnel constraints.

${ }^{b}$ Plant lodging ranked on scale of 0 to 10 , where 0 means no lodging and 10 means severe stalk lodging. $\dagger$ Dashes indicate missing data due to severe herbicide damage in Stratton in 2010. 
APPENDIX III

MY SORGHUM PRESENTATIONS

(EVENT, LOCATION, \& DATE)

\begin{tabular}{|c|c|c|}
\hline USDA Field Day & Akron, $\mathrm{CO}$ & June 2010 \\
\hline Sorghum Field Day & Akron, $\mathrm{CO}$ & September 2010 \\
\hline Sorghum Field Day & Brandon, $\mathrm{CO}$ & September 2010 \\
\hline Sorghum Field Day & Walsh, CO & September 2010 \\
\hline Colorado Ag. Classic & Loveland, CO & December 2010 \\
\hline Sorghum Producers Meeting & Granada, CO & February 2011 \\
\hline USDA Field Day & Akron, $\mathrm{CO}$ & June 2011 \\
\hline Sorghum Field Day & Akron, $\mathrm{CO}$ & September 2011 \\
\hline Sorghum Field Day & Brandon, $\mathrm{CO}$ & October 2011 \\
\hline Sorghum Field Day & Walsh, CO & October 2011 \\
\hline Colorado Ag. Classic & Loveland, CO & December 2011 \\
\hline USDA Stakeholder Meeting & Akron, $\mathrm{CO}$ & January 2012 \\
\hline Sorghum Producers Meeting & Granada, $\mathrm{CO}$ & March 2012 \\
\hline Soil \& Crop Sciences Seminar & Fort Collins, $\mathrm{CO}$ & March 2012 \\
\hline Thesis Defense & Fort Collins, $\mathrm{CO}$ & April 2012 \\
\hline USDA Field Day & Akron, $\mathrm{CO}$ & June 2012 \\
\hline
\end{tabular}

